\title{
Physical activity and sense of coherence: A meta-analysis
}

\author{
Susette A. Moyers ${ }^{1} \&$ Martin S. Hagger ${ }^{1,2}$ \\ ${ }^{1}$ Psychological Sciences, University of California, Merced \\ ${ }^{2}$ Faculty of Sport and Health Sciences, University of Jyväskylä
}

Susette A. Moyers ORCiD: 0000-0001-6867-2741 ${ }^{\mathrm{A}}$

Martin S. Hagger ORCiD: 0000-0002-2685-1546 ${ }^{\mathrm{B}}$

Full Citation: Moyers, S. A. \& Hagger, M. S. (2020). Physical activity and sense of coherence: A meta-analysis. International Review of Sport and Exercise Psychology. https://www.doi.org/10.1080/1750984X.2020.1846068

Correspondence concerning this article should be addressed to Susette A. Moyers, Social and Health Psychology Behavioral Research for Prevention and Promotion (SHARPP) Lab, Psychological Sciences, University of California, Merced, 5200 N. Lake Rd., Merced, CA 95343, USA. This study was preregistered in the Prospero registry of systematic reviews (https:// www.crd.york.ac.uk/prospero/), Prospero ID: CRD42020156095 


\begin{abstract}
The salutogenic model of health proposes that sense of coherence, a multi-dimensional construct representing individuals' perceptions that their environment is comprehensible, manageable, and meaningful, is a key determinant of stress management and well-being. Generalized resistance resources such as preventive health orientation, material resources, and social support are proposed as determinants of sense of coherence. Health behaviors, particularly physical activity, are proposed as indicators of a preventive health orientation and predictors of sense of coherence. We synthesized research on the relationship between physical activity and sense of coherence using three-level meta-analysis, and tested effects of key moderators of the relationship. Database and manual searches identified 52 studies meeting inclusion criteria with 73 effect sizes testing the relationship. The analysis revealed a small non-zero physical activitysense of coherence correlation with significant heterogeneity. Demographic variables, version of sense of coherence scale, physical activity measure, study design and quality, physical activity intensity, and time lag did not moderate the correlation. Findings suggest a robust but small correlation between physical activity participation and sense of coherence across studies. Studies that test the relationship using experimental or intervention designs, adopt more precise measures, and include measures of other health behaviors and generalized resistance resources are needed.
\end{abstract}

Keywords: Sense of coherence; Salutogenic model of health; Physical activity; Exercise; Generalized resistance resources; Health behavior 


\section{Physical Activity and Sense of Coherence: A Meta-Analysis}

\section{Introduction}

Stress exposure has been associated with the development or exacerbation of multiple physical and psychological health conditions including cardiovascular disease, type II diabetes, stroke (Rosmond \& Bjorntorp, 2000; Rosmond, 2003), cancer (Abercrombie et al., 2004; Lissoni et al., 2007; Reiche et al., 2004), premature cellular aging (Parks et al., 2009), autoimmune disorders, inflammation (Silverman \& Sternberg, 2012), systemic hypertension (Wirtz et al., 2007), depression (Stetler \& Miller, 2005; Dunn et al., 2001), and anxiety (Vedhara et al., 2003). Furthermore, national survey data demonstrates that individuals across the modern workforce are regularly exposed to stressors (American Psychological Association, 2017) and exhibit levels of stress that increase their risk of deleterious health outcomes in the long run (Wahrendorf \& Chandola, 2016). There is, therefore, a need for intervention strategies to assist individuals in managing stress effectively, which necessitates an understanding of the stress-coping process.

Numerous theoretical approaches have been applied to understand how stress appraisals and coping processes affect health outcomes. A prominent approach is the salutogenic model of health (Antonovsky, 1979). The model proposes that an individual's perceived available resources to manage stress and stress-related health outcomes are mediated by their sense of coherence. Sense of coherence is a multi-dimensional generalized construct representing the extent to which an individual perceives their environment as comprehensible, manageable, and meaningful. Individuals with a strong sense of coherence are able to systematically reflect on their internal and external environments, identify potential resources to cope with stress, and employ resources to resolve tension in a health promoting manner, attenuating the risks of stressrelated health outcomes, and promoting well-being (Antonovsky, 1979). According to the model, 
sense of coherence is determined by a set of generalized resistance resources, such as material resources, social support, and a preventive health orientation, which facilitate individuals' ability to manage the states of tension caused by stressors that potentially threaten health.

A preventive health orientation is a prominent generalized resistance resource in the model. The orientation is defined as the generalized tendency to engage in behaviors that mitigate or help manage stress (Rosenstock, 1974). Regular participation in health promoting behaviors (e.g., eating a healthy diet, attending health checks) is a clear indicator that an individual holds a preventive health orientation. According to the model, a preventive health orientation impacts stress-coping and subsequent health outcomes through the central mediator sense of coherence. As such, behaviors that are associated with having a preventive health orientation may directly impact sense of coherence. Regular participation in physical activity is a key health promoting behavior that indicates that an individual holds this preventive orientation. Participating in a given health-related behavior like regular physical activity may also indicate that an individual likely participates in multiple health behaviors (e.g., healthy eating, social distancing), which serve as further indicators of a preventive health orientation (Bourassa et al., 2020; Kremers et al., 2004). Research supporting the link between participation in health behaviors like physical activity and sense of coherence, therefore, provides indirect confirmation of the link between a preventive health orientation and sense of coherence, consistent with the model (Ahola et al., 2012; Myrin \& Lagerstrom, 2006; Öztekin \& Tezer, 2009).

Research has also supported the proposed direction of this relationship according to the model, such that physical activity participation predicts sense of coherence, with no effect in the opposite direction (Monma et al., 2017). However, other studies have suggested that sense of coherence impacts physical activity participation (Antonovsky, 1992; Myers et al., 2011). This 
may imply a dynamic relationship between these two variables, raising the prospect that the effects between them may be reciprocal.

However, the size of the physical activity participation-sense of coherence relationship across literature is inconsistent, with some studies reporting small-to-large effects (e.g., BinkowskaBury \& Januszewicz, 2010; Hassmen et al., 2000; Sipos et al., 2015; Kohut et al., 2006; Edwards, 2002), and others finding it to be no different from zero (e.g., Silarova et al., 2014; Kukihara et al., 2018). One reason for the observed variability may be the presence of sampling error or other sources of error, such as measurement error, across studies. Another reason may be that the variability is attributable to key moderator variables. Given the observed variability across studies, the aim of the current study was to test the overall size of the relationship between physical activity participation and sense of coherence, and estimate its true variability, by metaanalyzing the extant literature. Assuming significant between-study variability in the physical activity-sense of coherence relationship remains after correcting for sampling error within the studies through meta-analysis, we also aimed to explore effects of candidate moderators of the relationship. Analysis of moderators may assist in resolving the observed variability, and provide an indication of the specific methodological, sample-specific, or environmental conditions that may magnify or diminish the relationship. Finally, given research suggesting the effect may occur in both directions, the research also aimed to test whether the physical activity-sense of coherence relationship is reciprocal.

\section{Theoretical background}

The salutogenic model of health proposes potential pathways that explain how individuals cope with stress, which, in turn, impacts health-related outcomes (Antonovsky, 1979). A schematic representation of the model is presented in Figure 1. Individuals' knowledge of and 
capacity to utilize generalized resistance resources is proposed to impact sense of coherence (line A, Figure 1). Sense of coherence facilitates individuals' adaptation and coping processes through knowledge of, and the ability to mobilize, generalized resistance resources (line B) to either avoid the stressor (line C), re-appraise the stressor (line D), or successfully manage the stressor through holding action or taking action to overcome the stressor (line E). This process results in the success or failure of stress or tension management. Successful tension management reinforces sense of coherence (line F) through life experiences that are characterized by consistency, balance between under- and over-load, and participation in decision making (line G) and maintains health on the health 'ease-disease' continuum (line H). Unsuccessful tension management causes a state of stress, interacting with pathogens or 'weak links' that make one more susceptible to negative impacts on health status (line I). In moving towards 'ease' on the health spectrum, good health facilitates the acquisition of additional generalized resistance resources (line J). Each time an individual successfully manages stress and effectively alleviates tension, it is proposed that the individual moves toward better health outcomes, that is, toward the 'ease' side of the proposed 'ease-disease' health continuum.

[Insert Figure 1 near here]

\section{Sense of coherence}

The central determinant of successful tension management is sense of coherence. A strong sense of coherence is characterized by a global orientation comprised of three distinct facets: (a) comprehensibility - a pervasive, enduring dynamic feeling of confidence that stimuli from the person's external and internal environments are structured, predictable, and understood; (b) manageability - the belief in available resources the person has to offset demands imposed by these stimuli; and (c) meaningfulness - the belief that demands are challenges that are worth 
engagement (Antonovsky, 1987). The sense of coherence dimensions equally contribute to the overall sense of coherence and are inter-related yet explain unique variance in sense of coherence (Antonovsky, 1979). Sense of coherence is generally measured using the 29-item Sense of Coherence Scale, also referred to as the Orientation to Life Questionnaire, which was developed to measure the comprehensibility (11 items), manageability (10 items), and meaningfulness (8 items) dimensions, and has demonstrated adequate validity and reliability (Eriksson \& Lindström, 2005). Research reviews have indicated that individuals scoring higher on the overall scale have been found to manage stress more effectively than those with a lower score and have better physical and mental health outcomes (Eriksson \& Lindström, 2006).

\section{Generalized resistance resources}

A key determinant of sense of coherence is a set of generalized resistance resources, defined as "any physical, biochemical, artifactual-material, cognitive, emotional, valuative-attitudinal, interpersonal-relation, or macro sociocultural characteristic of an individual, primary group, subculture, or society that is effective in managing a wide variety of stressors and prevent tension from being transformed into health-threatening stress" (Antonovsky, 1979, p. 103). Examples of these resources include material resources, knowledge and intelligence, ego identity, coping strategies, social support, commitment and cohesion with cultural roots, cultural stability, ritualistic activities, religion/philosophy, genetic/constitutional factors, state of mind, and a preventive health orientation. Although, these resources are viewed as determinants of sense of coherence, theory and research has also indicated that individuals with a high sense of coherence may have more access to, and availability of, generalized resistance resources to cope with stressors, suggesting a reciprocal relationship between sense of coherence and generalized resistance resources (Moons \& Norekvål, 2006; Wolff \& Ratner, 1999; Antonovsky, 1987). 
While the generalized resistance resources are characterized as broad, general determinants of sense of coherence, it is important to study how specific instances of these resources contribute to sense of coherence. Such research will provide useful formative research to identify potentially manipulatable targets for behavioral intervention to promote successful stress coping (Hagger et al., 2020a).

One proposed specific generalized resistance resource is a preventive health orientation, defined as the generalized tendency to engage in behaviors that avoid stress (Rosenstock, 1974). Individuals with a preventive health orientation are more likely to engage in health promoting behaviors such as engaging in healthy sleep patterns, eating a healthy diet, adhering to disease screening behaviors, and participating in physical activity (Antonovsky \& Kats, 1970). This is consistent with research demonstrating that people's participation in different health behaviors tends to cluster together. For example, dietary behaviors have been shown to cluster together with physical activity behaviors (e.g., Kremers et al., 2004). Similarly, recent research has suggested that social distancing behaviors related to prevention of coronavirus transmission covaries with other health promoting behaviors like physical activity participation (Bourassa et al., 2020). Taken together, this research suggests that individuals who engage in a given health behavior are also more likely to participate in others, which is consistent with a generalized notion of a preventive health orientation governing this behavioral pattern. Individuals who participate in health behaviors on a regular basis because they have a high preventive health orientation are more likely to have a high sense of coherence, which, in turn, equips them to manage stress more effectively. This implies a mediation relationship in which sense of coherence mediates the effect of generalized resistance resources, such as a preventive health orientation, on stress-related outcomes. However, the model suggests that the pathway could also 
be reversed. For example, when a person with a high sense of coherence is confronted with a stressor that could threaten their health, they are more likely to respond with adaptive health behaviors, such as cutting back on smoking and drinking, being alert to threatening health symptoms, and engaging in physical activity (Antonovsky, 1987). Sense of coherence may, therefore, determine a preventive health orientation and participation in health behaviors.

\section{Physical activity and sense of coherence}

Research has begun to test how behaviors associated with a preventive health orientation are related to sense of coherence within the salutogenic model of health (Binkowska-Bury \& Januszewicz, 2010; Elyasi et al., 2015; Länsimies et al., 2017; Suraj \& Singh, 2011). Such relations provide indirect evidence for the preventive health orientation-sense of coherence relationship. One leading health-related behavior that represents an individuals' preventive health orientation is regular participation in physical activity. Within the model, health behaviors like physical activity are proposed be indicators of an individuals' preventive health orientation, which serves as a determinant of sense of coherence. This is illustrated in Figure 2, with physical activity represented as a specific behavior that comprises a preventive health orientation alongside other health behaviors (e.g., healthy eating, not smoking, moderating alcohol consumption, getting sufficient sleep, attending medical screening, oral hygiene behaviors, etc.). The preventive health orientation serves as a predictor of sense of coherence, consistent with the salutogenic model (path A). In addition, consistent with model proposals, preventive health orientation is one of a set of generalized resistance resources that are proposed to influence sense of coherence, so the parallel effects of other generalized resistance resources on sense of coherence is also illustrated (path B). It is important to note that researchers have used the relationship between individual behaviors, such as physical activity, and sense of coherence to 
infer a relationship between preventive health orientation and behavior and, more broadly, generalized resistance resources.

\section{[Insert Figure 2 near here]}

Consistent with the model, a growing body of research links regular participation in physical activity with a sense of coherence (Ahola et al., 2012; Myrin \& Lagerstrom, 2006; Öztekin \& Tezer, 2009; Read et al., 2005; Bergman et al., 2009; Kuuppelomäki \& Utriainen, 2003; Myers et al., 2011; Wainwright et al., 2007; Wainwright et al., 2008). This research provides preliminary evidence that physical activity, as a representative of a preventive health orientation is linked to sense of coherence. The link between physical activity and sense of coherence is representative of the effects of a preventive health orientation on sense of coherence, and provides a mechanistic explanation for the relationship. This also implies that the effects of physical activity, as an indicator of preventive health orientation, relate to health outcomes such as reduced stress and better well-being through the mediation of sense of coherence and there is some research illustrating this indirect relationship (Floyd, 2018; Kohut et al., 2005; Kohut et al., 2006; Kukihara et al., 2018; Read et al., 2005).

The physical activity participation-sense of coherence relationship is, therefore, an important one in the salutogenic model as it is an integral part of the process by which a preventive health orientation, as a key generalized resistance resource, relates to outcomes. However, although there a numerous tests of the association between physical activity and sense of coherence, considerable variability in the relationship has been observed. Some studies show large positive effects (Hassmen et al., 2000; Sipos et al., 2015; Kohut et al., 2006), while others show small (Edwards, 2002), or even null effects (Silarova et al., 2014; Kukihara et al., 2018). There may be a number of reasons for this observed variability. For example, the variation may be a function of 
methods adopted in the respective studies such as small sample sizes or measures that have low reliability. However, it may also be that the observed variability is a function of unmeasured moderator variables affecting the relationship across studies (e.g., different contexts, types of activity, sample-specific characteristics). For example, consistency of participation in physical activity, and the level of intensity with which it is performed, may indicate how strongly an individual endorses a preventive health orientation. In turn, the more strongly the individual endorses this particular generalized resistance resource, the stronger the effect on sense of coherence. So past history of physical activity participation (consistency) and how intensely it is performed, may be candidate moderators of the physical activity-sense of coherence relationship.

Synthesizing research on the physical activity-sense of coherence relationship would assist in resolving the observed variability in the effect across studies. Specifically, the application of a meta-analytic approach to synthesize data on the relationship across studies will enable estimation of the true variability in the physical activity participation-sense of coherence relationship after controlling for methodological artifacts (i.e., sampling error), and provide an indication of whether the relationship is affected by potential moderators. If the synthesized effect across studies exhibits substantive variability after correcting for within-study variability attributable to methodological artifacts like sampling error, it would catalyze a search for potential moderators of the effect. Candidate moderators of the effect might be type of physical activity performed, as suggested previously, as well as other sample-specific variables that have been identified as varying within groups in other samples looking at the physical activity participation and sense of coherence relationship, such as the age and sex of participants (Monma et al, 2015; Ahola et al, 2012).

\section{Unidirectional or reciprocal effects}


In addition, there is research proposing that the link between generalized resistance resources and sense of coherence is a dynamic process (Moons \& Norekvål, 2006; Wolff \& Ratner, 1999; Antonovsky, 1987). This may imply reciprocal relations between generalized resistance resources and sense of coherence such that resources like a preventive health orientation not only impact sense of coherence, but sense of coherence also serves to bolster preventive health orientation. As physical activity serves as an indicator of a preventive health orientation, it follows that physically active individuals may not only be more likely to report a greater sense of coherence, but individuals reporting higher sense of coherence are more likely to maintain participation in physical activity. There is preliminary evidence that may suggest this pattern of effects. For example, research using prospective designs has demonstrated that physical activity participation predicts sense of coherence (Kohut et al., 2006), and sense of coherence also predicts participation in physical activity (Myers et al., 2011). However, such directional effects cannot be unequivocally resolved through cross-sectional or longitudinal correlational research, and necessitate intervention, experimental, or panel designs. A panel design, for example, would entail measurement of both physical activity participation and sense of coherence concurrently over time, allowing for modeling of within-time and across-time relations and, importantly, cross-lagged effects. This pattern of effects illustrated in Figure 3 and adoption of this design would allow for a test of whether the relationship is unidirectional or reciprocal.

To date, only one study has adopted a cross-lagged, synchronous panel design permitting a test of reciprocal relations between physical activity participation and sense of coherence (Monma et al., 2017). Findings revealed time-lagged and cross-lagged effects of physical activity on sense of coherence, but did not support sense of coherence as a predictor of physical activity participation. These data provide preliminary support for role of physical activity as a 
determinant of sense of coherence, consistent with the model and indicative of a unidirectional effect. However, these findings contrast with other research adopting prospective designs demonstrating effects of sense of coherence on physical activity participation without testing reciprocal effects (Myers et al., 2011; Kohut et al., 2006). Testing the physical activity participation-sense of coherence relationship in both directions in a cross-lagged panel design model based on synthesized data across studies may provide more robust, converging evidence as to whether the effect is unidirectional or reciprocal.

[Insert Figure 3 near here]

\section{The present study}

The aim of the present study was to synthesize research testing the physical activity participation-sense of coherence relationship and examine the effects of candidate moderators of the relationship across populations. More specifically, we first aimed to determine the size and variability of the correlation between physical activity participation and sense of coherence across studies in existing literature using three-level meta-analysis. The rationale behind this aim was to evaluate whether the observed variability in the correlation across studies could be attributed solely to methodological artifacts corrected for in meta-analysis (i.e., sampling error) or reflects true variability across studies.

Second, we aimed to test effects of candidate moderators (age, sex, version of the sense of coherence scale, physical activity measurement, study design, physical activity intensity, study quality, and time lag) on the physical activity participation-sense of coherence correlation across studies, using categorical moderator analyses and meta-regression. For the sense of coherence and physical activity measurement moderators, we predicted that studies adopting non-self-report measures of physical activity (e.g., use of accelerometers or pedometers) would 
exhibit greater precision and less variability than studies adopting self-reported physical activity measures, as self-reported physical activity be subject to biases attributable to socially desirable responding and limitations of recall (Sallis \& Saelens, 2005; Adams et al., 2005). Studies adopting full versions of the SOC scale and previously-validated physical activity scales were expected to report greater precision and less variability in the averaged physical activity participation-sense of coherence relationship compared to studies adopting truncated versions of the scale and bespoke measures of physical activity. This is because full versions of the measures of SOC and previous-validated physical activity scales are likely to have better reliability and validity than truncated and bespoke versions, respectively (Eriksson \& Lindström, 2005; Milton et al., 2011). With respect to the age and sex moderator variables, we expected that age and sex may moderate the physical activity participation-sense of coherence relationship, with larger effects expected in males and younger samples consistent with previous studies (Monma et al, 2015, Ahola et al, 2012). We also predicted that lower quality studies were likely to exhibit greater error variance in the averaged physical activity participation-sense of coherence relationship relative to studies of acceptable quality. We made no predictions on the direction of the moderation as error variance has been shown to inflate and attenuate relations between variables (Johnson et al., 2014).

We also expected studies adopting correlational designs to have a larger averaged physical activity participation-sense of coherence relationship than studies employing experimental or intervention designs. This is because correlational studies tend to use similar methods and measure constructs in close proximity, therefore inflating relations due to common method variance and measurement correspondence. We also expected that participants engaging in higher intensity physical activity may reflect greater investment in a preventive health 
orientation, so we expect the averaged physical activity participation-sense of coherence metaanalytic estimate to be larger in groups of studies on participants participating in higher intensity activities compared to studies on participants with general or light activity intensity (Rhodes \& De Bruijn, 2010; Teixeira et al., 2012).

Finally, we aimed to test available evidence for the directional nature of the relationship between physical activity participation and sense of coherence by examining the time-lagged effects between these variables (i.e., studies measuring physical activity at one time point and a follow-up measure of sense of coherence and vice-versa), as well as experimental studies manipulating one of the variables and examining its effect on the other. Such research may shed light on the direction of the relationship between physical activity participation and sense of coherence, or whether a reciprocal relationship exists.

\section{Method}

Study methods and analyses were submitted for pre-registration with the Prospero registry for systematic reviews (Prospero ID: CRD42020156095). Two search methods were utilized to identify studies for inclusion. First, a keyword search was conducted in six electronic databases: Web of Science, Scopus, PsycINFO, EBSCO, JSTOR, and PubMed using the following search string: 'sense of coherence' OR 'sense of coherence scale' OR 'orientation to life' OR ‘Orientation to Life Questionnaire’ OR ‘OLQ’ OR ‘salutogene*’ OR ‘Antonovsky’ AND 'physical activity' OR 'exercise' OR 'fitness' OR 'cardio training' OR 'strength training' OR 'resistance training' OR 'endurance training' OR 'weight training' OR 'sport*' OR 'energy expenditure' OR 'caloric expenditure' OR 'cycling*' OR 'jogging' OR 'swimming' OR 'running' OR 'physical education'. The search was not limited by language or publication year, and included research items available during or before June 2019. Second, manual searches of 
the reference lists of pertinent review and overview articles were conducted. Prominent authors in the field were also contacted and asked to supply any unpublished data. Requests for data were circulated on the listservs of relevant organizations in October 2019 (e.g., Society for Behavioral Medicine; Society for Personality and Social Psychology).

\section{Inclusion/exclusion criteria}

Published research, unpublished theses, abstracts, dissertations, and manuscripts were eligible for inclusion. Studies were included if they fulfilled two criteria: (1) the study utilized any version of the sense of coherence scale (e.g., any version of the Orientation to Life Questionnaire, or the Sense of Coherence scale, including full and shortened versions; Antonovsky, 1987), and (2) the study included at least one measure of physical activity participation, defined as participation in exercise, sport, or physical activities as part of daily living, occupation, leisure, and active transportation (Garber et al., 2011). Studies adopting both self-report and non-self-report (e.g., accelerometers, pedometers) measures of physical activity were included to ensure our search was optimally inclusive. Studies were included regardless whether physical activity participation and sense of coherence were treated within the study as predictor variables, outcome variables, or both, and whether physical activity participation and sense of coherence were measured concurrently or in a time-lagged longitudinal design. Studies on participants with impaired capacity to provide responses on self-report questionnaires were excluded. Studies with proxy measures (e.g., parent, caregivers) of study constructs or outcomes were excluded.

\section{Study search and initial screening}

Authors were contacted if physical activity data were collected as part of a global 'health behavior' measure, but isolated effects of physical activity participation were not reported. 
Authors were also contacted if physical activity participation and sense of coherence were measured in a study, but the physical activity participation-sense of coherence relationship was not reported or reported in a multivariate analysis from which a unique physical activity participation-sense of coherence effect size could not be isolated. In cases where interventions or experimental studies employed a manipulation of physical activity participation or change in sense of coherence, then the effect of the manipulation on the outcome was taken as the estimate of the effect. If the experimental manipulation consisted of multiple components, targeted an outcome other than physical activity or sense of coherence, targeted more than one outcome, or did not specify the target construct or behavior, then data at baseline or in the control group were used to estimate the effect where possible, otherwise the authors were contacted to supply data. After removal of duplicate studies, 1494 studies were identified for inclusion. Of these, 233 were excluded after title screening and a further 1050 studies excluded after abstract screening. Main reasons for exclusion included: articles were theoretical or conceptual reviews, systematic reviews, and off-topic (not pertaining to any content related to physical activity participation or sense of coherence). Remaining articles $(k=211)$ were subjected to full-text analysis for inclusion in the final sample, of these, 159 did not meet criteria for inclusion. Studies were excluded at this stage for the following reasons: no measure of the sense of coherence scale was included; no measure of physical activity participation was included; the article reported a theoretical review or study protocol, or reported results of a qualitative study; the data reported duplicated those used in another record; or insufficient data were available in the article to compute effect sizes and authors could not be contacted or were unable to supply the required data. The final sample of longitudinal and experimental studies did not permit a test the reciprocal relationship of the physical activity-sense of coherence relationship, as we specified in 
our aims. This was because there were few longitudinal studies measuring relations between sense of coherence and physical activity across time. However, in particular, there were very few studies that tested time-lagged relations between physical activity measured, or manipulated, at an initial point in time and sense of coherence measured at a subsequent point in time. Study selection procedures are summarized in the PRISMA (Moher et al., 2009) flow diagram in Appendix A (supplemental materials).

\section{Data extraction}

Titles and abstracts of the articles retrieved in search were screened against inclusion/exclusion criteria. This comprised an initial title screen, followed by abstract and full text screening. Title and abstract screening were conducted by the lead researcher and two trained research assistants. During title screening, articles were divided into retained, excluded, or potentially eligible categories. Queries raised during screening were discussed between the research team and resolved through mutual agreement. Full text articles of retained and potentially eligible studies were assessed for inclusion. Full text screening was conducted by the lead researcher and one trained research assistant, with $25 \%$ of the articles screened by both researchers to validate the screening procedure. Agreement between the reviewers was calculated with $93.33 \%$ agreement $(\kappa=.853,[0.712,0.995], p<.001)$. Disagreements were also resolved through discussion and inclusion/exclusion criteria were modified and reapplied if necessary.

Study characteristics, effect size data, and data for moderator variable coding were extracted from all eligible articles by the lead researcher and cross-checked for accuracy by a senior researcher. Extracted data included author names, publication year, study design, sample type and characteristics (gender, age, final sample size), sense of coherence scale form (29-item version, 13-item version, or measures with fewer than 13 items), physical activity measure 
(previously-validated physical activity scales, or bespoke physical activity related questions), and physical activity intensity included in the measurement (no indication of intensity, light, moderate-vigorous, or mixed physical activity intensities). Effect size data for relations between sense of coherence and physical activity were extracted from included studies by two lead researchers.

The zero-order correlation coefficient $(r)$ was selected as the effect size metric as the majority of the studies were expected to be correlational in design and $r$ was expected to be the most frequently adopted effect size. Where effect sizes were not expressed as a correlation, an effect size estimate was derived from available data including computed effect sizes (Cohen's $d$ or $f$, eta-squared), tests of difference (e.g., $t$ and $F$-ratios, chi-square values) and converted to $r$ using standard formulae (Borenstein et al., 2009). In cases where data for one of the target variables was expressed as a categorical variable, with means and standard deviations for the other variable for each category, we computed a standardized mean difference using the available data and converted to $r$. For experimental or intervention studies, we computed an effect size using baseline and follow-up data for the dependent variable for either the experimental or control group (controlled designs), or baseline to follow-up (pre-post designs) manipulations of the independent variable (Borenstein et al., 2009).

Where studies reported multiple effect sizes for the physical activity participation-sense of coherence relationship within each study, we treated each effect size according to a predefined protocol. Studies reporting separate effects sizes estimated in two or more independent samples were treated as separate studies. Where multiple effect sizes were reported in same study, such studies reporting correlations between a measure of sense of coherence and more than one measure of physical activity, these effect sizes were treated as multiple effect sizes from 
the same study. We therefore coded the data according to whether effects sizes were from independent samples or multiple effect sizes within a single study, this coding was used as input for subsequent data analysis. Coding of how effect sizes were treated is summarized in Appendix B (supplemental materials), with information on how each study was coded provided in Appendix C (supplemental materials). Study authors were contacted to request any missing data within a reasonable time frame.

\section{Assessment of study quality}

The quality of all studies, including unpublished studies ${ }^{1}$, was assessed using the Quality Assessment Checklist for Survey Studies in Psychology (Q-SSP; Protogerou \& Hagger, 2020). The Q-SSP is a quality rating measure for survey studies in psychology. The checklist comprises 20 items assessing quality criteria in four domains: introduction (rationale/variables), participants (sampling/recruitment), data (collection/analyses/measures/results/discussion), and ethics. Each item receives either a 'yes' response indicating that the criterion is met in the study, a 'no' response indicating that the criterion is not met or there is insufficient data available to determine whether or not the study meets the criterion, or a 'not applicable' response indicating that the criterion is not met for the study. An overall quality score is computed for each study by dividing the total number of 'yes' scores by the total number of applicable items, and cut-off values for acceptable and questionable study quality are then applied to produce a binary study quality score for each study. The binary score served as a moderator of the averaged corrected effect sizes for the relationship between physical activity participation and sense of coherence in the meta-analysis. Data were not available for one unpublished conference abstract that met

${ }^{1}$ The final sample of studies included unpublished dissertations ( $\mathrm{k}=5$; Floyd, 2007; Lei, 2009; Nagata, 2017; Santhouse, 2008; Skirka, 2000), an unpublished conference paper (Endo et al., 2012a), and an unpublished conference abstract (Endo et al., 2012b). 
inclusion criteria (Endo et al., 2012b), and data could not be sourced from the author. Therefore, the quality score for this study was treated as missing data in our analyses.

\section{Meta-analytic methods}

The average sample-weighted correlation $(r)$ between physical activity participation and sense of coherence was computed using three-level random-effects meta-analytic methods implemented using the metafor package (Viechtbauer, 2010) in R. Three-level or 'multi-level' meta-analysis was used because some of the studies in the sample of included studies that reported multiple effect sizes for the physical activity participation-sense of coherence relationship. This was due to studies reporting effect sizes from multiple measures of physical activity within the same sample rather than independent samples. This is problematic because it violates the assumption of independence of each effect size included in the analysis. So variation in effect sizes within studies was treated as a separate artifact of variance in the analysis. Three-

level meta-analysis, therefore, provides sample-weighted averaged effect size estimates corrected for between- and within-study variance $\left(\sigma^{2}\right)$ components separately, enabling researchers to correct for both variance components simultaneously as well as estimate the degree to which each variance component contributes to overall variability across the studies (Assink \& Wibblink, 2016). We used our coding of studies as independent effect sizes or as effect sizes within a single study (see Appendix B \& C, supplemental materials) to designate studies according to the different variance components in the three-level meta-analysis. Contribution of the between- and -within study variance to the total variance in the physical activity participation-sense of coherence relationship across studies, as well the proportion of total variance attributable to sampling error is provided by Cheung's (2014) formula.

Alongside the averaged sample-weighted correlation corrected for variance components, 
several tests of the heterogeneity of the averaged correlations were computed. Specifically, we computed the Cochran's $Q$ and $I^{2}$ coefficients (Higgins \& Thompson, 2002). Statistically significant $Q$ values and $I^{2}$ values exceeding $25 \%$ are indicative of substantial heterogeneity in correlations (Higgins \& Thompson, 2002).

Small-study bias in the effect size was assessed using a funnel plot of the sense-ofcoherence-physical activity correlation from each study on study precision (e.g., the reciprocal of the study sample size). Asymmetry in the funnel plot suggests evidence of small-study bias, which could inflate effect size estimates. This is often used to infer publication bias. A formal test of bias based on the funnel plot is given by a regression test in which study effect sizes from the sample of studies are regressed on their precision estimates based on the standard error (see Egger \& Sterne, 2005). The analysis not only indicates the extent of asymmetry in the funnel plot with a formal test, but also provides a corrected 'bias free' estimate of the averaged effect size. We computed two versions of the test, one in which study effect size is regressed on the standard error (the precision effect test; PET) and another in which study effect size is regressed on the square of the standard error (the precision effect estimate with standard error; PEESE) (Stanley \& Doucouliagos, 2014). PET and PEESE estimates for each effect size were computed, with accompanying $t$-tests for bias and significance tests of the corrected effect from zero, using the PETPEESE function in R (Carter et al., 2019). Consistent with Stanley and Doucouliagos' (2014) rule, if the PET estimate for the effect size is non-zero, the PEESE estimate is used as the corrected value, while when it is no different from zero, the PET estimate is used.

Effects of categorical moderator variables were tested by conducting separate metaanalyses for correlations between physical activity participation and sense of coherence in groups of studies defined by each level of the moderator where there were at least two studies at each 
level of the moderator. Comparisons across moderator groups were made using $95 \%$ confidence intervals about the averaged sample-weighted correlations in each moderator using Schenker and Gentleman's (2001) standard method (Schenker \& Gentleman, 2001). Multivariate metaregression analyses were conducted to examine the effects of moderators that were continuous in format (e.g., study quality, time lag between data collection). Meta-regressions also allowed for the examination of unique effects of categorical and continuous moderator variables.

\section{Results}

\section{Study characteristics}

Fifty-two articles were included reporting a total of 61 independent effect sizes for the physical activity participation-sense of coherence relationship. A number of studies also included multiple effect size estimates within studies (e.g., studies reporting correlations between sense of coherence and multiple measures of physical activity, see Appendix B, supplemental materials), resulting in a final sample of 73 effect sizes for analysis. Study characteristics, details of the outcome measures, moderator coding, and raw effect sizes for the physical activity participationsense of coherence relationship in each study are provided in Appendix C (supplemental materials), a full list of studies included in the meta-analysis is presented in Appendix D (supplemental materials), and a PRISMA checklist (Moher et al., 2009) is provided in Appendix E (supplemental materials). ${ }^{2}$

Studies utilized a range of sense of coherence measures, including the 29-item $(k=26)$ and 13-item $(k=40)$ versions of the Sense of Coherence Scale (Antonovsky, 1987), and bespoke scales comprising fewer than 13 items $(k=7)$. Studies also utilized previously-validated selfreport measures of physical activity such as the International Physical Activity Questionnaire

\footnotetext{
${ }^{2}$ The data file used in the meta-analysis including effect sizes and moderator coding is available online: https://osf.io/fv6n4/?view_only=58dade398bc045f38c981091a61e98c9
} 
(IPAQ; Sjöström, Bull, \& Craig, 2002) or the Godin-Shephard Leisure-Time Physical Activity Questionnaire (GSLTPAQ; Godin, 2011) $(k=11)$, while others adopted bespoke short-form single or multiple item self-reports of physical activity $(k=62)$. No studies utilized non-selfreport measures of physical activity such as accelerometers or pedometers.

\section{Overall effect size}

Results of the three-level meta-analysis are reported in Table 1. Results indicated that the model correcting for within-study sampling variance (level 1) accounted for a significant proportion of the variance in the effect across studies, while the variance accounted for by differences between effect studies within studies (level 2) did not. This was confirmed by performing separate meta-analyses and comparing the variance accounted for in each restricted model with the overall model that included both variance components (Table 1). We therefore took the analysis correcting only for within-study sampling variance as the most precise point estimate and variability of the effect size based on the current set of studies. The analysis revealed a small non-zero overall sample-weighted average effect size for the relationship between self-reported physical activity participation and sense of coherence $(r=0.125,95 \% \mathrm{CI}$ $[0.082,0.168])$. However, the proportion of the total variance in effect sizes across studies attributable to within-study sampling error (4.42\%) and effect sizes within studies (6.80\%) was small compared to the proportion attributable to between-study variance $(88.78 \%)$. This was corroborated by the heterogeneity statistics for the model: $Q(72)=778.286, p<.001 ; I^{2}=$ $94.88 \%, 95 \%$ CI $[93.56,97.20]$. This suggested the potential presence of moderators of the effect size.

[Insert Tables 1 and 2 near here]

\section{Moderator analyses}


Results of the categorical moderator variable analysis are presented in Table 2. Despite observed differences in the averaged effect sizes across moderator groups, there was substantive overlap in the confidence intervals about each effect size for all analyses. This was mirrored in the heterogeneity statistics for the effect size in each moderator group, which indicated that considerable heterogeneity remained in the majority of cases and suggested that the moderators did not reduce the variability and lead to any narrowing of the confidence intervals. Furthermore, formal difference tests in effect sizes across moderator categories using the confidence intervals about the mean difference, revealed no significant differences, suggesting that the none of the candidate moderator variables moderated the self-reported physical activity participation-sense of coherence relationship. While the effect size for studies using previously validated physical activity scales did not indicate substantial heterogeneity, it must be stressed that mean difference tests did not indicate a significant difference between measuring physical activity participation with a previously validated scale versus utilizing bespoke measures of physical activity.

\section{Small study bias}

A 'funnel' plot of the corrected effect size for each study against its precision (standard error) is presented in Appendix F. Regression tests based on the funnel plot revealed statistically significant effects for the precision estimator on the effect size for the PET $\left(\mathrm{B}_{1}=0.452,95 \% \mathrm{CI}\right.$ $[0.061,0.842], p=0.023)$ and PEESE $\left(\mathrm{B}_{1}=4.288,95 \% \mathrm{CI}[1.443,7.133], p=0.003\right)$ versions of the test. As the PET estimate for the effect size was non-zero, the PEESE estimate was taken as the corrected value for the physical activity participation-sense of coherence effect size $\left(\mathrm{B}_{0}=\right.$ $0.102,95 \%$ CI $[.092, .112], p<.0001)$. These findings provided some evidence of small study bias in our sample of studies, but the corrected value provided by the regression test did not 
differ substantially from the original estimate and suggests that the effect of the bias did not alter our conclusions on the size and variability of the averaged effect size across studies.

\section{Discussion}

Based on Antonovsky's (1979) salutogenic model of health, the aim of the current preregistered study was to synthesize research testing the relationship between physical activity participation and sense of coherence using three-level meta-analysis. We also examined effects of candidate moderators of the relationship. Specifically, we estimated the size and variability of the correlation between physical activity participation and sense of coherence across studies using three-level meta-analysis. Next, we tested the effects of several candidate moderators (age, sex, version of the sense of coherence scale, physical activity measurement, study design, physical activity intensity, study quality, and time lag) on the physical activity participationsense of coherence relationship across studies, using categorical moderator analyses and metaregression. The analysis revealed 73 independent effect sizes for the physical activity-sense of coherence relationship, all of which relied exclusively on self-reported physical activity.

Findings revealed a small non-zero averaged corrected correlation between self-reported physical activity participation and sense of coherence. The effect size exhibited substantive heterogeneity across studies that could not be attributed to the methodological artifacts corrected for in the meta-analysis, suggesting the presence of moderators. Planned moderator analyses revealed no statistically significant differences in the self-reported physical activity participation-sense of coherence effect size across studies at across levels of all moderators. However, it is worth noting that the effect size in studies using validated physical activity scales was a homogenous case with narrow confidence intervals. Finally, there were insufficient data to fulfil our preregistered aim of testing reciprocal effects between physical activity and sense of coherence. 
The small non-zero correlation between self-reported physical activity participation and sense of coherence was consistent with the size of effects observed in many primary studies (Ahola et al., 2012; Myrin \& Lagerstrom, 2006; Öztekin \& Tezer, 2009.; Read et al., 2005; Bergman et al., 2009; Kuuppelomäki \& Utriainen, 2003; Myers et al., 2011; Wainwright et al., 2007; Wainwright et al., 2008; Edwards, 2002). Overall, current data suggest that self-reported physical activity is consistently related to sense of coherence across studies. The small size of the effect is commensurate with the generalized nature of the sense of coherence construct. Sense of coherence is measured as a generalized orientation and is, therefore, expected to have consistent relations with determinants of stress management, such as generalized resistance resources, and outcomes, such as stress management and health across multiple contexts and populations. However, by definition, effect sizes of such generalized dispositions will be relatively small given their global nature and lack of measurement correspondence, consistent with research on other traits and dispositions such as personality dimensions (Ashton et al., 2014). In addition, the model suggests that a preventive health orientation is one of a number of generalized resistance resources that are related to sense of coherence. In fact, physical activity is only one of many preventive health behaviors that are likely to represent a preventive health orientation, and correlate with sense of coherence. Future syntheses or research on the salutogenic model should consider the potential relations between other constructs and variables that are proposed as generalized resistance resources and sense of coherence. Such an analysis should not only consider univariate relations between different measures of generalized resistance resources and sense of coherence, but also multivariate effects and the directionality of the effects.

However, although the physical activity-sense of coherence effect size was robust, its small magnitude raises questions as to its practical utility. One of the goals of the salutogenic 
model of health is to provide a basis for intervention to promote better stress coping and improve well-being. For example, it may assist in in identifying modifiable targets such as generalized resistance resources that are reliably related to sense of coherence and adaptive health-related outcomes which, if changed through intervention, may lead to concomitant change in the outcomes. Given that the effect size for the physical activity-sense of coherence relationship is non-zero across multiple studies suggests that physical activity participation satisfies at least one important criterion as a potential intervention target: that it is a reliable correlate. In addition, although the effect size is small, even small effects can have a large impact at scale, something which has been reported extensively in medical and health contexts more broadly (NordahlHansen, et al. 2018).

However, there are a number of important caveats which need to be considered when interpreting these findings and their value in informing interventions. First, the extent to which the target is modifiable needs to be established. In the case of physical activity, there is good evidence that physical activity can be changed through intervention (e.g., Gourlan et al., 2016). Second, confirmatory evidence that changing the target, in this case physical activity, leads to concomitant change in the outcome, sense of coherence and, indirectly, stress management and well-being is needed (Hagger et al., 2020b). The current meta-analysis does not contribute to supporting this premise. Granted there is some evidence that increased physical activity through intervention leads to changes in sense of coherence (Gustavsson \& Bränholm, 2003; Kekäläinen et al., 2018; Kohut et al., 2006), but the convergence and robustness of this evidence is in question given that we had insufficient intervention studies in the current research to metaanalyze these effects. Then there is the issue of whether changes in sense of coherence led to changes in outcomes, for which, again, the evidence is less robust. Finally, there is the issue of 
the size of the effect itself. An intervention aimed at changing a variable (e.g., physical activity) which has a small effect on an outcome (e.g., sense of coherence) will have very little impact the outcome if the intervention effect is small. In the current context, this means that any intervention targeting change in physical activity will have to have a large effect on physical activity if that change is to be transmitted to changes in sense of coherence. So even reliable effects may not have practical utility if interventions do not have the sufficient 'strength' to lead to large changes in the target behavior. Taken together, we cannot conclude on the basis of the current data whether the small but robust relationship between physical activity and sense of coherence will have practical or clinical significance in informing interventions. Further research supporting the effectiveness of physical activity interventions in changing sense of coherence, and the size of those effects, is needed to ascertain such a perspective.

\section{Analysis of moderators}

Tests of heterogeneity of the physical activity participation-sense of coherence relationship indicated that substantive heterogeneity remained after correcting the effect for sampling error in the meta-analysis. This prompted tests of a series of candidate moderators of the physical activity participation-sense of coherence relationship with the goal of resolving the observed heterogeneity in the effect across studies. Tests of categorical moderators (age, sex, version of the sense of coherence scale, physical activity participation measurement, study design, physical activity intensity, study quality) did not indicate any moderator effects, with no large observed difference in the effect size across moderator categories and substantive overlap in the confidence intervals surrounding the effect sizes. Similarly, meta-regression including both continuous and categorical moderator variables revealed no statistically significant moderator effects. 
Importantly, age and sex did not emerge as significant moderators of the relationship. Some studies in this literature have shown age and sex related differences in this relationship (Monma et al, 2015, Ahola et al, 2012) and many studies control for these demographic variables by convention when testing relations between physical activity participation and sense of coherence. However, it seems that such controls may not be necessary and that the overall effect size is relatively invariant across age groups and gender. In addition, while the analysis of type of physical activity measure yielded no difference in the size of the effect across studies using bespoke physical activity measures and validated physical activity participation measures, results indicated that studies using the latter measures exhibited a homogenous effect size with narrow confidence intervals. This suggests that studies using these measures leads to more precision in the effect. Findings suggest, therefore, that use of validated measures eliminates some of the measurement error associated with the effect size and provides preliminary evidence of the virtue of selecting measures that are likely to yield greater accuracy in the estimation of physical activity.

However, it is important to note that these findings were based on a relatively small sample of studies so inferences based on these findings should interpreted with that caveat in mind. Furthermore, we were only able to analyze effects of physical activity measure type and physical activity intensity as moderators. While we identified regularity and type of activity as other physical activity characteristics which may have served to moderate the physical activitysense of coherence correlation, there was insufficient data in the included studies to test these effects. This was mainly because the majority of studies used bespoke measures of physical activity that did not include this information and precluded coding of a meaningful moderator variable. Future studies testing the physical activity-sense of coherence relationship should 
consider using measures that also capture the type and regularity of physical activity, which would contribute toward future syntheses with these variables as moderators.

\section{Strengths, limitations, and future directions}

The current study had numerous strengths: (a) Use of meta-analytic data from multiple studies across populations to test the relationship between self-reported physical activity participation and sense of coherence; (b) Use of three-level random-effects meta-analytic methods to correct studies for variability attributable to within- and between-study variance components; and (c) Testing effects of key moderator variables of the relationship. Overall, current findings are expected to guide future research by identifying the strength of the evidence for one of the key correlates of sense of coherence, variables that may affect the relationship, and gaps in current evidence.

However, it would be remiss not to mention some pertinent limitations of the analysis which place limits on its generalizability, but also provide impetus for future research. First, the current study solely focused on the physical activity participation-sense of coherence relationship. Physical activity participation is one health behavior that is considered to indicative of a preventive health orientation. However, the salutogenic model also suggests that other health behaviors indicate a preventive health orientation, such as healthy dietary behaviors or participation in medical screening, which may also contribute to explaining variance in sense of coherence. Furthermore, there are a number of other generalized resistance resources that are postulated to relate to sense of coherence which may serve to further explain variance in sense of coherence. Future research should synthesize the literature on links between other health behaviors that are associated with a preventive health orientation (e.g., screening behaviors, healthy dietary practices) as well as other known generalized resistance resources that may 
impact this relationship. The small effect size also likely represents the generalized nature of the measure and the constructs of sense of coherence. Consistent with research on many individual differences constructs that are generalized constructs, their effects tend to be weak. Future research should consider measuring domain-specific forms of sense of coherence (e.g., work sense of coherence; Bauer et al., 2015), which may lead to larger effects.

A key limitation of the current study is the preponderance of studies adopting correlational designs. Importantly, intervention studies focused on the manipulation of physical activity through intervention and testing effects on sense of coherence, but by contrast there were only four experimental or intervention studies with available data affecting change in sense of coherence through manipulation of physical activity participation. This means that current data cannot be used to make causal inferences on the effect between physical activity as a generalized resistance resource and sense of coherence. Although we set out to test the proposed directionality of the effect implied by the theory using a reciprocal effects panel design, currently available data precluded such an analysis. As the research literature examining longitudinal relations between physical activity participation and sense of coherence proliferates, future syntheses examining reciprocal effects in a cross-lagged panel design may be possible (see Figure 3). Studies that manipulate sense of coherence and examine effects of generalized resistance resources, like physical activity, would also be a useful addition to the literature, although means to reliably manipulate sense of coherence need to be developed. This would provide stronger evidence for the causal direction of the effects.

A related limitation of the current analysis and, by extension, the current literature on physical activity and sense of coherence, is that it is relatively silent on the mechanisms by which physical activity relates to sense of coherence. In the model, physical activity is proposed 
to reflect or represent a preventive health orientation, yet there is little direct evidence to support this premise. For example, few studies have directly measured a preventive health orientation alongside physical activity behavior and examined correlations between these variables. Furthermore, preventive health orientation is proposed as just one of a series of generalized resistance resources proposed to give rise to and bolster sense of coherence (see Figure 2). Again, little data is offered to support links between measures of health behaviors and a measure of preventive health orientation. Finally, and most importantly, there is little evidence measuring the indirect effect of physical activity, or other health behaviors, on sense of coherence mediated by a measure of preventive health orientation. The mechanism for the proposed mechanism by which physical activity relates to sense of coherence is, therefore, is inferred by theory not the data. This gives rise to a series of important issues that have important ramifications for the salutogenic model of health and how the field should move forward in confirming its predictions.

First, links between physical activity participation, preventive health orientation, and generalized resistance resources should be confirmed empirically. Specifically, the strength of the relationship between physical activity and preventive health orientation needs to be established, and its potential mediation role in the relationship with sense of coherence need to be ascertained. A further important question is the size of the physical activity-preventive health orientation relationship when other health behaviors are taken into account. Given that health behaviors tend to cluster together (Kremers et al., 2004; Bourassa et al., 2020), there may be a level of redundancy, and it would be interesting to see whether a particular behavior seems to 'win out' as a correlate of a preventive health orientation, whether all contribute equally, or whether there are within-person or group-level preferences that determine which behavior makes the strongest contribution. The same question should be levelled at the relationship between 
preventive health orientation and sense of coherence -to what extent does the orientation contribute to explaining variance in sense of coherence when other generalized resistance resources are taken into account? What is needed to respond to these questions are comprehensive longitudinal or panel design studies that include measures of multiple health behaviors, multiple generalized resistance resources, preventive health orientation, and sense of coherence. This would provide the opportunity to test the pattern of effects proposed in Figure 2, consistent with model predictions. Such research may yield data that moves the field forward in terms of understanding the mechanisms by which health behaviors like physical activity link with sense of coherence.

While we found no moderator effects of the self-reported physical activity participationsense of coherence relationship in the current set of studies, this should not be taken as definitive evidence for the null effects of these moderators. A number of caveats to the current analysis and the available data should be taken into account when interpreting these findings. First, imprecision of moderator measurement may have impacted results; many of the moderators were based on self-report and the potential for measurement error pertaining to affirmation bias and socially desirable responding to have affected results cannot be ruled out. It is notable that studies relied exclusively on self-report measures of physical activity. Self-report measures are subject to reporting bias attributable to a social desirability and recall (Sallis \& Saelens, 2005; Adams et al., 2005). This may have introduced considerable error variance in the physical activity-sense of coherence relationship, which may have had the effect of inflating or attenuating observed effects. Adoption of non-self-report measures of physical activity in future studies may lead to greater precision in the physical activity participation-sense of coherence relationship and resolve some of the variability in the effect across studies (Prince et al., 2008). 
Second, coding of variables to allow for moderator analysis may have meant some loss of fidelity in the moderator variables. For example, sex was coded as majority female ( $>=75 \%)$, mixed (between $26 \%$ and $74 \%$ female), and majority male participants ( $<=25 \%$ female). Some samples may have been on the edge of these cutoffs (e.g., the sample was $26 \%$ female but was classified as mixed based on cutoff criteria), resulting in a reduced ability to detect moderating effects. However, such classification was necessary due to the relatively small sample of studies testing the physical activity participation-sense of coherence effect. As the research in this domain expands, researchers may be able produce moderator groups with greater precision and provide more rigorous tests of moderator effects. Finally, while we planned to include ethnicity as a moderator, only four of the included studies reported measures of the ethnicity of the sample. Future research should aim to incorporate ethnicity in the measurement of this relationship to enable testing ethnicity as a potential moderator of the physical activity participation-sense of coherence relationship. In addition, some articles identified as eligible for inclusion in our search did not report sufficient data to compute useable effect sizes for analysis and data were not available on request, therefore, eligible articles were excluded on this basis. This limitation highlights the imperative for greater accessibility of research data in this domain. Proliferation of studies that include more precise measures and greater diversity in sample characteristics and contexts may allow for more fine-grained moderator analyses. There is also a need for more primary research that provides more rigorous tests of the physical activity participation-sense of coherence relationship, particularly using better measures and designs.

\section{Conclusion}

Based on the salutogenic model of health, this study utilized meta-analytic methods to estimate the size and variability of the relationship between physical activity participation and 
sense of coherence across the extant literature. Overall findings from the meta-analysis revealed a small non-zero averaged corrected correlation between self-reported physical activity participation and sense of coherence, suggesting a small role for physical activity as a generalized resistance resource. However, the effect size exhibited substantive heterogeneity across studies that could not be attributed to sampling error. Moderator analyses revealed no statistically significant differences in the effect size of the relationship across studies at different levels of the moderator variables, suggesting that the current set of moderators did not resolve observed heterogeneity in the effect. Results also identify some key evidence gaps, particularly in the need for longitudinal and experimental literature on the physical activity participationsense of coherence relationship, inclusion of non-self-report physical activity measures, and the need to measure key moderators such as sample ethnicity. Future research may aim to fill these gaps, as well as to test other potential preventive behaviors that may contribute to sense of coherence. There is also a need for studies that review and quantify the effects of other proposed generalized resistance resources in the salutogenic model to understand unique contribution each makes to explaining variance in sense of coherence. This research may provide valuable data on the relative contribution that different generalized resistance resources make to the prediction of sense of coherence, which may then be utilized to intervene to improve sense of coherence, and, indirectly, stress-coping and stress-related outcomes.

\section{Acknowledgements}

We thank the following authors for providing requested data for this analysis;

Konstantinos G. Baxevanos, Michal Bronikowski, Anna Daderman, Shintaro Endo, Sophia Jörgensen, Torunn Hatlen Nøst, Kasper Olesen, Chris J. Packard, Jochen Mayer, Ulrich Wiesmann, Shinichi Nagata, \& Åse Hansen. 


\section{Declaration of Interest}

Martin S. Hagger's contribution was supported by Finland Distinguished Professor (FiDiPro) grant from Business Finland (Grant \#1801/31/2015). Study materials, data files, data analysis scripts, and analysis output presented in this manuscript can be found at https://osf.io/fv6n4/?view_only=58dade398bc045f38c981091a61e98c9. We have no conflicts of interest to disclose. 


\section{References}

Abercrombie, H. C., Giese-Davis, J., Sephton, S., Epel, E. S., Turner-Cobb, J. M., \& Spiegel, D. (2004). Flattened cortisol rhythms in metastatic breast cancer patients.

Psychoneuroendocrinology, 29(8), 1082-1092.

https://doi.org/10.1016/J.PSYNEUEN.2003.11.003

Adams, S. A., Matthews, C. E., Ebbeling, C. B., Moore, C. G., Cunningham, J. E., Fulton, J., Hebert, J. R. (2005). The effect of social desirability and social approval on self-reports of physical activity. American Journal of Epidemiology; 161(4), 389-

398. https://doi.org/10.1093/aje/kwi054

Ahola, A. J., Mikkilä, V., Saraheimo, M., Wadén, J., MäkimaTtila, S., Forsblom, C., Freese, R., \& Groop, P.-H. (2012). Sense of coherence, food selection and leisure time physical activity in type 1 diabetes. Scandinavian Journal of Public Health, 40(7), 621-628. https://doi.org/10.1177/1403494812460346

American Psychological Association. (2017). Stress in America: The state of our nation. https:// www.apa.org/news/press/releases/stress/2017/state-nation.pdf

Antonovsky, A. (1979). Health, stress and coping. San Francisco: Jossey-Bass.

Antonovsky A. (1987). Unraveling the mystery of health. How people manage stress and stay well. San Francisco: Jossey-Bass.

Antonovsky, A. (1992). Can attitudes contribute to health? Advances, 8(4), 33-49.

Antonovsky, A., \& Kats, R. (1970). The model dental patient: An empirical study of preventive health behavior. Social Science \& Medicine, 4(4), 367-380. https://doi.org/10.1016/0037$\underline{7856(70) 90075-2}$

Ashton, M. C., Lee, K., \& de Vries, R. E. (2014). The HEXACO honesty-humility, 
agreeableness, and emotionality factors: A review of research and theory. Personality and Social Psychology Review, 18(2), 139-152. https://doi.org/10.1177/1088868314523838

Assink, M., \& Wibbelink, C. J. M. (2016). Fitting three-level meta-analytic models in R: A stepby-step tutorial. The Quantitative Methods for Psychology, 12(3), 154-174. https://doi.org/10.20982/tqmp.12.3.p154

Bauer, G. F., Vogt, K., Inauen, A., \& Jenny, G. J. (2015). Work-soc-development and validation of a scale measuring work-related sense of coherence. Zeitschrift für Gesundheitspsychologie, 23(1), 20-30. https://doi.org/10.1026/0943-8149/a000132

Bergman, E., Malm, D., Karlsson, J.E., \& Berterö, C. (2009). Longitudinal study of patients after myocardial infarction: Sense of coherence, quality of life, and symptoms. Heart \& Lung, 38(2), 129-140. https://doi.org/10.1016/J.HRTLNG.2008.05.007

Binkowska-Bury, M., \& Januszewicz, P. (2010). Sense of coherence and health-related behaviour among university students-a questionnaire survey. Central European Journal of Public Health, 18(3), 145.

Borenstein, M., Hedges, L. V., Higgins, J. P. T., \& Rothstein, H. R. (2009). Introduction to meta-analysis. Wiley. https://doi.org/10.1002/9780470743386

Bourassa, K. J., Sbarra, D. A., Caspi, A., \& Moffitt, T. E. (2020). Social distancing as a health behavior: County-level movement in the United States during the COVID-19 pandemic is associated with conventional health behaviors. Annals of Behavioral Medicine, 54(8). 548556. https://doi.org/10.1093/abm/kaaa049

Carter, E. C., Schönbrodt, F. D., Gervais, W. M., \& Hilgard, J. (2019). Correcting for bias in psychology: A comparison of meta-analytic methods. Advances in Methods and Practices in Psychological Science, 2(2), 115-144. https://doi.org/10.1177/2515245919847196 
Cheung, M. W. L. (2014). Modeling dependent effect sizes with three-level meta-analyses: A structural equation modeling approach. Psychological Methods, 19(2), 211-229. https://doi.org/10.1037/a0032968

Dunn, A. L., Trivedi, M. H., \& O’Neal, H. A. (2001). Physical activity dose-response effects on outcomes of depression and anxiety. Medicine and Science in Sports and Exercise, 33(6 Suppl), S587-97; discussion 609-10. https://doi.org/10.1097/00005768-200106001-00027

Dutta, M. J., \& Bodie, G. (2006). Health orientation as a predictor of exercising: A psychographic approach. Social Marketing Quarterly, 12(4), 3-18. https://doi.org/10.1080/15245000600993045

Edwards, S. (2002). Physical exercise and psychological wellness. International Journal of Mental Health Promotion, 4(2), 40-46. https://doi.org/10.1080/14623730.2002.9721860

Egger, M., \& Sterne, J. A. C. (2005). Regression methods to detect publication and other bias in meta-analysis. In H. Rothstein, A. Sutton \& M. Borenstein (Eds.), Publication bias and meta-analysis: Prevention, assessments and adjustments (pp. 99-109). Wiley.

Elyasi, M., Abreu, L. G., Badri, P., Saltaji, H., Flores-Mir, C., \& Amin, M. (2015). Impact of sense of coherence on oral health behaviors: A systematic review. PloS One, 10(8), e0133918. https://doi.org/10.1371/journal.pone.0133918

Endo, S., Kanou, H., \& Oishi, K. (2012a). Sports activities and sense of coherence (SOC) among college students. International Journal of Sport and Health Science, 10(0), 1-11. https://doi.org/10.5432/ijshs.201114

Endo, S., Kanou, H., \& Oishi, K. (2012b, May). Relationship between the habit of exercise and sense of coherence among retired males in Japan. Medicine and Science in Sports and Exercise; (Conference Abstract, Vol. 44, pp. 812-813). 
Eriksson, M., \& Lindström, B. (2005). Validity of Antonovsky's sense of coherence scale-a systematic review. Journal of Epidemiology \& Community Health, 59(6), 460-466. http://dx.doi.org/10.1136/jech.2003.018085

Eriksson, M., \& Lindström, B. (2006). Antonovsky's sense of coherence scale and the relation with health: A systematic review. Journal of Epidemiology \& Community Health, 60(5), 376-381. http://dx.doi.org/10.1136/jech.2005.041616

Floyd, A. R. (2007). Sense of coherence and quality of life in lung cancer: Potential psychological, behavioral and biological mediators. [Doctoral dissertation; University of Louisville].

Garber, C. E., Blissmer, B., Deschenes, M. R., Franklin, B. A., Lamonte, M. J., Lee, I. M., ... \& Swain, D. P. (2011). Quantity and quality of exercise for developing and maintaining cardiorespiratory, musculoskeletal, and neuromotor fitness in apparently healthy adults. Medicine \& Science in Sports \& Exercise, 43(7), 1334-1359. https://doi.org/10.1249/MSS.0b013e318213fefb

Godin, G. (2011). The Godin-Shephard leisure-time physical activity questionnaire. The Health \& Fitness Journal of Canada, 4(1), 18-22. https://doi.org/10.14288/hfjc.v4i1.82

Gourlan, M., Bernard, P., Bortholon, C., Romain, A. J., Lareyre, O., Carayol, M., Ninot, G., \& Boiché, J. (2016). Efficacy of theory-based interventions to promote physical activity. A meta-analysis of randomised controlled trials. Health Psychology Review, 10(1), 50-66. https://doi.org/10.1080/17437199.2014.981777

Gustavsson, A., \& Bränholm, I. B. (2003). Experienced health, life satisfaction, sense of coherence, and coping resources in individuals living with heart failure._Scandinavian Journal of Occupational Therapy,_10(3), 138-143. 
https://doi.org/10.1080/11038120310016120

Hagger, M, S., Moyers, S., McAnally, K., \& McKinley, L. E. (2020a). Known knowns and known unknowns on behavior change interventions and mechanisms of action. Health Psychology Review, 14(1), 199-212. https://doi.org/10.1080/17437199.2020.1719184

Hagger, M. S., Cameron, L. D., Hamilton, K., Hankonen, N., \& Lintunen, T. (Eds.). (2020b).

The handbook of behavior change. Cambridge University Press. https://doi.org/10.1017/9781108677318.

Hassmen, P., Koivula, N., \& Uutela, A. (2000). Physical exercise and psychological well-being: A population study in Finland. Preventive Medicine, 30(1), 17-25. https://doi.org/10.1006/pmed.1999.0597

Higgins, J. P., \& Thompson, S. G. (2002). Quantifying heterogeneity in a meta-analysis. Statistics in Medicine, 21(11), 1539-1558. https://doi.org/10.1002/sim.1186

Johnson, B. T., Low, R. E., \& MacDonald, H. V. (2014). Panning for the gold in health research: Incorporating studies' methodological quality in meta-analysis. Psychology \& Health, 30(1), 135-152. https://doi.org/10.1080/08870446.2014.953533

Kekäläinen, T., Kokko, K., Sipilä, S., \& Walker, S. (2018). Effects of a 9-month resistance training intervention on quality of life, sense of coherence, and depressive symptoms in older adults: Randomized controlled trial. Quality of Life Research, 27(2), 455-465. https:// doi.org/10.1007/s11136-017-1733-Z

King, A. C., Baumann, K., O'Sullivan, P., Wilcox, S., \& Castro, C. (2002). Effects of moderateintensity exercise on physiological, behavioral, and emotional responses to family caregiving: A randomized controlled trial. The Journals of Gerontology Series A: Biological Sciences and Medical Sciences, 57(1), M26-M36. 
https://doi.org/10.1093/gerona/57.1.M26

Kohut, M. L., Lee, W., Martin, A., Arnston, B., Russell, D. W., Ekkekakis, P., Yoon, J., Bishop, A., \& Cunnick, J. E. (2005). The exercise-induced enhancement of influenza immunity is mediated in part by improvements in psychosocial factors in older adults. Brain, Behavior, and Immunity, 19(4), 357-366. https://doi.org/10.1016/j.bbi.2004.12.002

Kohut, M. L., McCann, D. A., Russell, D. W., Konopka, D. N., Cunnick, J. E., Franke, W. D., Castillo, A. E., Reighard, A. E., \& Vanderah, E. (2006). Aerobic exercise, but not flexibility/resistance exercise, reduces serum IL-18, CRP, and IL-6 independent of $\beta$ blockers, BMI, and psychosocial factors in older adults. Brain, Behavior, and Immunity, 20(3), 201-209. https://doi.org/10.1016/j.bbi.2005.12.002

Kremers, S. P. J., de Bruijn, G.-J., Schalmaa, H., \& Brug, J. (2004). Clustering of energy balance related behaviours and their intrapersonal determinants. Psychology and Health, 19, 595606. https://doi.org/10.1080/08870440412331279630

Kukihara, H., Yamawaki, N., Ando, M., Tamura, Y., Arita, K., \& Nakashima, E. (2018). The mediating effects of resilience, morale, and sense of coherence between physical activity and perceived physical/mental health among Japanese community-dwelling older adults: A cross-sectional study. Journal of Aging and Physical Activity, 26(4), 544-552. https://doi.org/10.1123/japa.2017-0265

Kuuppelomäki, M., \& Utriainen, P. (2003). A 3-year follow-up study of health care students' sense of coherence and related smoking, drinking and physical exercise factors. International Journal of Nursing Studies, 40(4), 383-388. https://doi.org/10.1016/S0020$\underline{7489(02) 00103-7}$

Länsimies, H., Pietilä, A. M., Hietasola-Husu, S., \& Kangasniemi, M. (2017). A systematic 
review of adolescents' sense of coherence and health. Scandinavian Journal of Caring Sciences, 31(4), 651-661. https://doi.org/10.1111/scs.12402

Lei, Y. (2019). The effects of a strengths-based intervention based on salutogenic model on selfcare behaviors and sense of coherence in older adults with type 2 diabetes. [Doctoral dissertation; The Chinese University of Hong Kong].

Lissoni, P., Brivio, F., Fumagalli, L., Messina, G., Secreto, G., Romelli, B., ... \& Brera, G. (2007). Immune and endocrine mechanisms of advanced cancer-related hypercortisolemia. In Vivo, 21(4), 647-650.

Lutz, R. S., Lochbaum, M. R., Lanning, B., Stinson, L. G., \& Brewer, R. (2007). Cross-lagged relationships among leisure-time exercise and perceived stress in blue-collar workers. Journal of Sport and Exercise Psychology, 29(6), 687-705. https://doi.org/10.1123/jsep.29.6.687

Milton, K., Bull, F. C., \& Bauman, A. (2011). Reliability and validity testing of a single-item physical activity measure. British Journal of Sports Medicine, 45(3), 203-208. http://dx.doi.org/10.1136/bjsm.2009.068395

Moher, D., Liberati, A., Tetzlaff, J., Altman, D. G., \& the PRISMA Group. (2009). Preferred reporting items for systematic reviews and meta-analyses: The PRISMA statement. PLOS Medicine, 6(7), e1000097. https://doi.org/10.1371/journal.pmed.1000097

Moons, P., \& Norekvål, T. M. (2006). Is sense of coherence a pathway for improving the quality of life of patients who grow up with chronic diseases? A hypothesis. European Journal of Cardiovascular Nursing, 5(1), 16-20. https://doi.org/10.1016/j.ejcnurse.2005.10.009

Monma, T., Takeda, F., \& Okura, T. (2017). Physical activities impact sense of coherence among community-dwelling older adults. Geriatrics \& Gerontology International, 17(11), 
2208-2215. http://doi.org/10.1111/ggi.13063

Myers, V., Drory, Y., \& Gerber, Y. (2011). Sense of coherence predicts post-myocardial infarction trajectory of leisure time physical activity: A prospective cohort study. $B M C$ Public Health, 11(1), 708. https://doi.org/10.1186/1471-2458-11-708

Myrin, B., \& Lagerstrom, M. (2006). Health behaviour and sense of coherence among pupils aged 14-15. Scandinavian Journal of Caring Sciences, 20(3), 339-346. https://doi.org/10.1111/j.1471-6712.2006.00413.x

Nagata, S. (2017). Leisure and symptoms of depression: Identification of the role of leisuregenerated resources, physical activity, and sense of coherence. [Doctoral dissertation, Indiana University].

Nordahl-Hansen, A., Øien, R. A., Volkmar, F., Shic, F., \& Cicchetti, D. V. (2018). Enhancing the understanding of clinically meaningful results: A clinical research perspective. Psychiatry Research, 270, 801-806. https://doi.org/10.1016/j.psychres.2018.10.069

Öztekin, C., \& Tezer, E. (2009). The role of sense of coherence and physical activity in positive and negative affect of Turkish adolescents. Adolescence: An International Quarterly Devoted to the Physiological, Psychological, Psychiatric, Sociological, and Educational Aspects of the Second Decade of Human Life, 44(174), 421-432. https://search.proquest.com/docview/195940179?accountid=14515

Parks, C. G., Miller, D. B., McCanlies, E. C., Cawthon, R. M., Andrew, M. E., DeRoo, L. A., \& Sandler, D. P. (2009). Telomere length, current perceived stress, and urinary stress hormones in women. Cancer Epidemiology, Biomarkers \& Prevention: A Publication of the American Association for Cancer Research, Cosponsored by the American Society of Preventive Oncology, 18(2), 551-560. https://doi.org/10.1158/1055-9965.EPI-08-0614 
Prince, S. A., Adamo, K. B., Hamel, M. E., Hardt, J., Gorber, S. C., \& Tremblay, M. (2008). A comparison of direct versus self-report measures for assessing physical activity in adults: A systematic review. International Journal of Behavioral Nutrition and Physical Activity, 5(1), 56. https://doi.org/10.1186/1479-5868-5-56

Protogerou, C., \& Hagger, M. S. (2020). Development of a checklist to assess the quality of survey studies in psychology. Retrieved January 31, 2020, from https://osf.io/xgy69/

Read, S., Aunola, K., Feldt, T., Leinonen, R., \& Ruoppila, I. (2005). The relationship between generalized resistance resources, sense of coherence, and health among Finnish people aged 65-69. European Psychologist, 10(3), 244-253. https://doi.org/10.1027/1016-9040.10.3.244

Reiche, E. M. V., Nunes, S. O. V., \& Morimoto, H. K. (2004). Stress, depression, the immune system, and cancer. The Lancet Oncology, 5(10), 617-625. https://doi.org/10.1016/S1470$\underline{2045(04) 01597-9}$

Rhodes, R. E., \& De Bruijn, G. J. (2010). Automatic and motivational correlates of physical activity: Does intensity moderate the relationship? Behavioral Medicine, 36(2), 44-52. https://doi.org/10.1080/08964281003774901

Rosenstock, I. M. (1974). The health belief model and preventive health behavior. Health Education Monographs, 2(4), 354-386. https://doi.org/10.1177/109019817400200405

Rosmond, R., \& Bjorntorp, P. (2000). The hypothalamic-pituitary-adrenal axis activity as a predictor of cardiovascular disease, type 2 diabetes and stroke. Journal of Internal Medicine, 247(2), 188-197. https://doi.org/10.1046/j.1365-2796.2000.00603.x

Rosmond, R. (2003). Stress induced disturbances of the HPA axis: A pathway to type 2 diabetes? Medical Science Monitor, 9(2), RA35-RA39.

Sallis, J. F., \& Saelens, B. E. (2005). Assessment of physical activity by self-report: Status, 
limitations, and future directions. Research Quarterly for Exercise and Sport, 71: sup2, 114. https://doi.org/10.1080/02701367.2000.11082780

Santhouse, R. (2008). Correlates of service utilization and adherence to dietary and exercise modifications in a sample of women before and after bariatric surgery. [Doctoral dissertation, University of Pittsburgh].

Schenker, N., \& Gentleman, J. F. (2001). On judging the significance of differences by examining the overlap between confidence intervals. The American Statistician, 55(3), 182-186. https://doi.org/10.1198/000313001317097960

Silarova, B., Nagyova, I., Rosenberger, J., Studencan, M., Ondusova, D., Reijneveld, S. A., \& van Dijk, J. P. (2014). Sense of coherence as a predictor of health-related behaviours among patients with coronary heart disease. European Journal of Cardiovascular Nursing, 13(4), 345-356. http://doi.org/10.1177/1474515113497136

Silverman, M. N., \& Sternberg, E. M. (2012). Glucocorticoid regulation of inflammation and its functional correlates: From HPA axis to glucocorticoid receptor dysfunction. Annals of the New York Academy of Sciences, 1261(1), 55-63. https://doi.org/10.1111/j.1749$\underline{6632.2012 .06633 . x}$

Sipos, E., Jeges, S., \& Tóth, Á. (2015). Sport, sense of coherence, and self-esteem among 16 and 17-year-olds. European Journal of Mental Health, 10(1), 62-77. https://doi.org/10.5708/EJMH.10.2015.1.4

Sjöström, M., Bull, F., \& Craig, C. (2002). Towards standardized global assessment of healthrelated physical activity-the International Physical Activity Questionnaire (IPAQ). Medicine \& Science in Sports \& Exercise, 34(5), S202. https://doi.org/10.1097/00005768$\underline{200205001-01140}$ 
Skirka, N. (2000). The relationship of hardiness, sense of coherence, sports participation, and gender to perceived stress and psychological symptoms among college students. [Doctoral dissertation, New York University].

Stanley, T. D., \& Doucouliagos, H. (2014). Meta-regression approximations to reduce publication selection bias. Research Synthesis Methods, 5(1), 60-78. https://doi.org/10.1002/ jrsm.1095

Stetler, C., \& Miller, G. E. (2005). Blunted cortisol response to awakening in mild to moderate depression: Regulatory influences of sleep patterns and social contacts. Journal of Abnormal Psychology, 114(4), 697-705.https://doi.org/10.1037/0021-843X.114.4.697

Stults-Kolehmainen, M. A., \& Sinha, R. (2014). The effects of stress on physical activity and exercise. Sports Medicine, 44(1), 81-121. https://doi.org/10.1007/s40279-013-0090-5

Suraj, S., \& Singh, A. (2011). Study of sense of coherence health promoting behavior in north Indian students. The Indian Journal of Medical Research, 134(5), 645. https://doi.org/10.4103/0971-5916.90989

Teixeira, P. J., Carraça, E. V., Markland, D., Silva, M. N., \& Ryan, R. M. (2012). Exercise, physical activity, and self-determination theory: A systematic review. International Journal of Behavioral Nutrition and Physical Activity, 9(1), 78. https://doi.org/10.1186/1479-5868$\underline{9-78}$

Vedhara, K., Miles, J., Bennett, P., Plummer, S., Tallon, D., Brooks, E., ... Farndon, J. (2003). An investigation into the relationship between salivary cortisol, stress, anxiety and depression. Biological Psychology, 62(2), 89-96. https://doi.org/10.1016/S0301$\underline{0511(02) 00128-X}$

Viechtbauer, W. (2010). Conducting meta-analyses in R with the metafor package. Journal of 
Statistical Software, 36(3), 1-48. https://doi.org/10.18637/jss.v036.i03

Wahrendorf, M., \& Chandola, T. (2016) A life course perspective on work stress and health. In: Siegrist J., \& Wahrendorf M. (Eds.) Work stress and health in a globalized economy. Aligning perspectives on health, safety and well-being (pp. 43-66). Springer.

Wainwright, N. W. J., Surtees, P. G., Welch, A. A., Luben, R. N., Khaw, K.-T., \& Bingham, S. A. (2008). Sense of coherence, lifestyle choices and mortality. Journal of Epidemiology \& Community Health, 62(9), 829-831. https://doi.org/10.1136/jech.2007.066464

Wainwright, N. W. J., Surtees, P. G., Welch, A. A., Luben, R. N., Khaw, K.-T., \& Bingham, S. A. (2007). Healthy lifestyle choices: Could sense of coherence aid health promotion? Journal of Epidemiology \& Community Health, 61(10), 871-876. https://doi.org/10.1136/JECH.2006.056275

Wilcox, S., Dowda, M., Leviton, L. C., Bartlett-Prescott, J., Bazzarre, T., Campbell-Voytal, K., ... \& Griffin, S. F. (2008). Active for life: Final results from the translation of two physical activity programs. American Journal of Preventive Medicine, 35(4), 340-351. https://doi.org/10.1016/j.amepre.2008.07.001

Wirtz, P. H., von Känel, R., Emini, L., Ruedisueli, K., Groessbauer, S., Maercker, A., \& Ehlert, U. (2007). Evidence for altered hypothalamus-pituitary-adrenal axis functioning in systemic hypertension: Blunted cortisol response to awakening and lower negative feedback sensitivity. Psychoneuroendocrinology, 32(5), 430-436. https://doi.org/10.1016/j.psyneuen.2007.02.006

Wolff, A. C., \& Ratner, P. A. (1999). Stress, social support, and sense of coherence. Western Journal of Nursing Research, 21(2), 182-197. https://doi.org/10.1177/01939459922043820 
Figure 2. Relationships between a preventive health orientation, other generalized resistance resources (GRRs), and sense of coherence

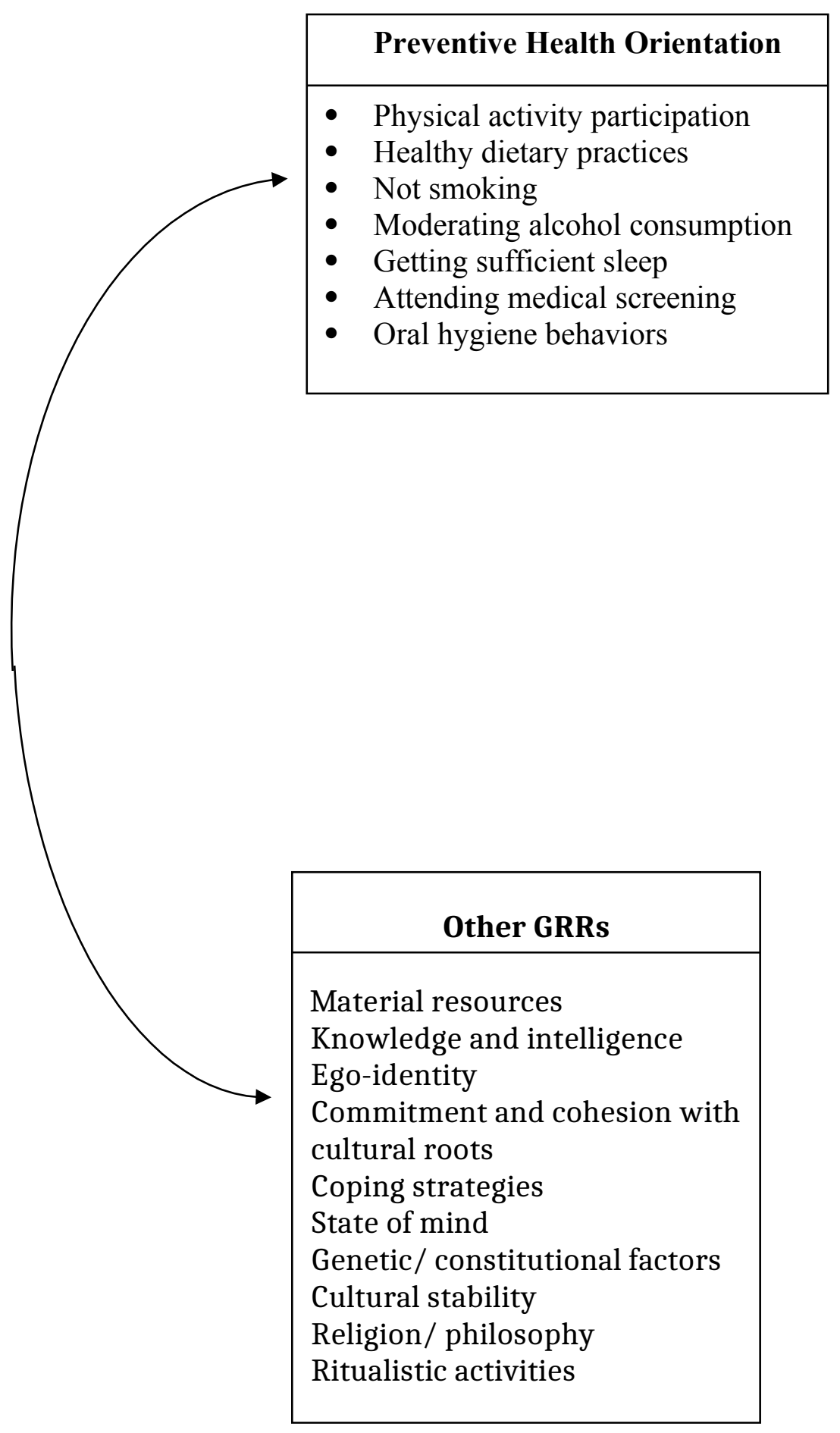

Note. Physical activity participation and participation other health behaviors represent one generalized resistance resource; a preventive health orientation. A preventive health orientation (path A), along with other generalized resistance resources (path B), predict sense of coherence in the salutogenic model of health. 
Figure 3. Proposed reciprocal effects model for physical activity participation and sense of coherence.

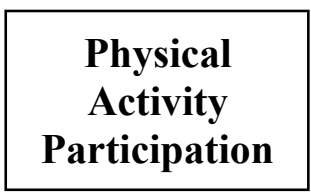

Sense of

Coherence

\section{Physical \\ Activity \\ Participation}

Sense of Coherence 


\section{Appendix A. PRISMA Flow Diagram}

\section{Figure A1}

Flow Diagram Illustrating Literature Search and Study Selection and Retention in Meta-Analysis
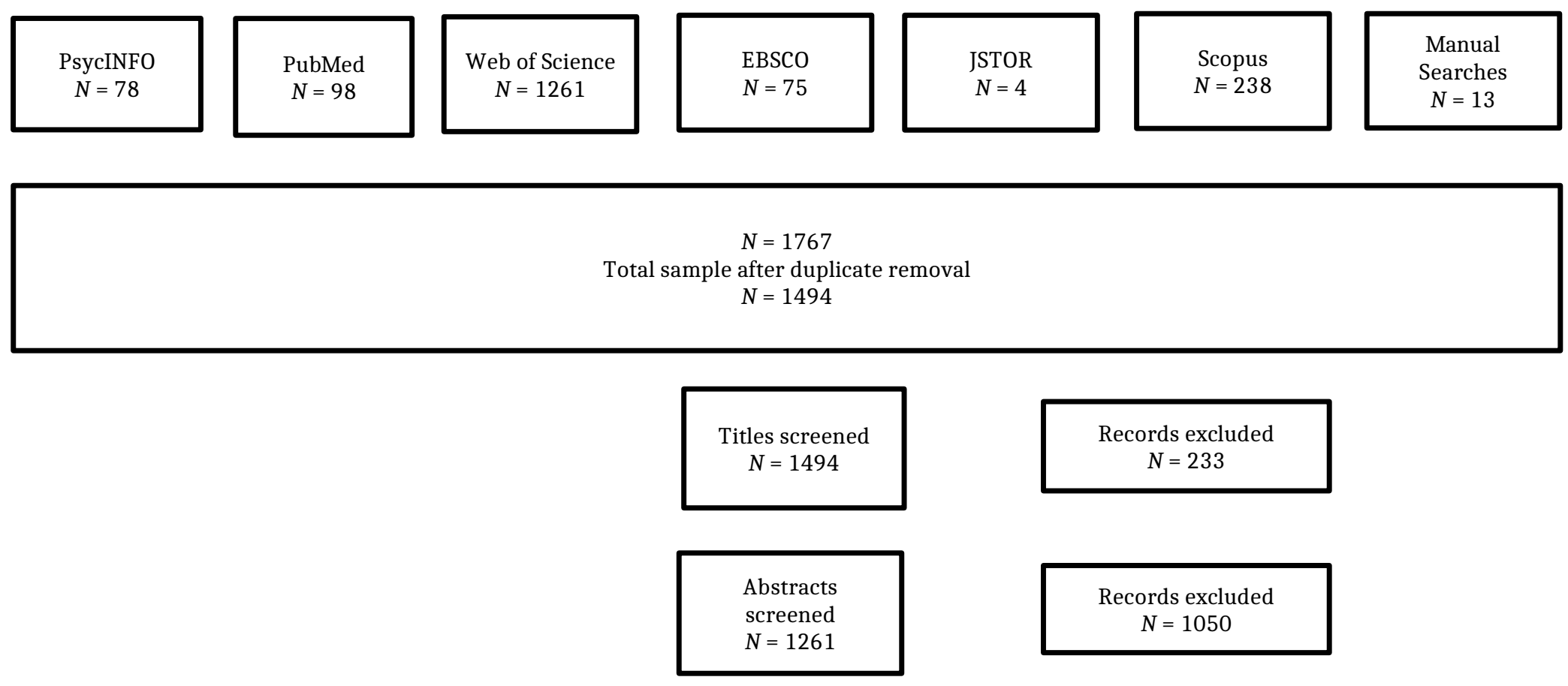

Records excluded

$$
N=1050
$$
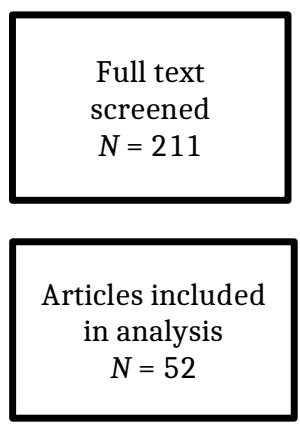

$$
\begin{gathered}
\text { Correlations } \\
\text { included in } \\
\text { analysis } \\
N=73
\end{gathered}
$$

Records excluded, with reasons $N=159$

Qualitative study $(N=3)$

Protocol $(N=2)$

Theoretical $(N=1)$

No PA measurement or insufficient

measurement $(N=81)$

No SOC measurement $(N=4)$

Insufficient data to compute effect size $(N=57)$

-Author unable to be contacted $(N=46$

articles)

-Author unable to supply necessary data $(N=$

11 articles)

-Author emailed wrong stat $(N=1)$

Data duplicated in another record $(N=10)$ 


\section{Appendix B. Multiple and Overlapping Studies}

Table B1

Studies Included in Meta-Analysis with Multiple Samples or Measures of Constructs

\begin{tabular}{|c|c|c|c|}
\hline Study & Samples $^{\mathrm{a}}$ & $\begin{array}{l}\text { Multiple measures of physical activity } \\
\text { constructs }^{\text {b }}\end{array}$ & Treatment $^{\mathrm{c}}$ \\
\hline $\begin{array}{l}\text { Hansen Ã. M., Grynderup, } \\
\text { M. B., Rugulies, R., } \\
\text { Conway, P. M., Garde, A. } \\
\text { H., Török, E., Mikkelsen, } \\
\text { E. G., Persson, R., Hogh, } \\
\text { A. }\end{array}$ & 1 & 2 timepoints (06' and 08') & $\begin{array}{l}\text { Separate } \\
\text { measures }\end{array}$ \\
\hline $\begin{array}{l}\text { Holmberg, S., Thelin, A., } \\
\text { \& Stiernström, E. L. } \\
(2004)\end{array}$ & 1 & $\begin{array}{l}3 \text { constructs (sedentary vs. vigorously } \\
\text { active; slightly vs. vigorously active; } \\
\text { moderate vs. vigorously active) }\end{array}$ & $\begin{array}{l}\text { Separate } \\
\text { measures }\end{array}$ \\
\hline $\begin{array}{l}\text { Kekäläinen, T., Kokko, } \\
\text { K., Sipilä, S., \& Walker, } \\
\text { S. (2018) }\end{array}$ & 1 & $\begin{array}{l}4 \text { constructs (baseline- } 3 \text { months; control vs. } \\
\text { resistance training once a week | baseline- } 3 \\
\text { months; control vs. resistance training } 3 \\
\text { times a week | baseline- } 6 \text { months; control } \\
\text { vs. resistance training once a week | } \\
\text { baseline- } 6 \text { months; control vs. resistance } \\
\text { training } 3 \text { times a week) }\end{array}$ & $\begin{array}{l}\text { Separate } \\
\text { measures }\end{array}$ \\
\hline $\begin{array}{l}\text { Kohut, M. L., McCann, D. } \\
\text { A., Russell, D. W., } \\
\text { Konopka, D. N., Cunnick, } \\
\text { J. E., Franke, W. D., } \\
\text { Castillo, M. C., Reighard, } \\
\text { A. E., \& Vanderah, E. } \\
\text { (2006) }\end{array}$ & 2 & $\begin{array}{l}2 \text { conditions (cardio training and resistance } \\
\text { training) }\end{array}$ & $\begin{array}{l}\text { Separate } \\
\text { samples }\end{array}$ \\
\hline $\begin{array}{l}\text { Mayer, J., \& Thiel, A. } \\
\text { (2015) }\end{array}$ & 2 & 1 construct & $\begin{array}{l}\text { Separate } \\
\text { samples } \\
(\mathrm{M} / \mathrm{F})\end{array}$ \\
\hline $\begin{array}{l}\text { Myrin, B. \& Lagerstrom, } \\
\text { M. (2006) }\end{array}$ & 2 & $\begin{array}{l}2 \text { constructs (leisure time PA and sports } \\
\text { participation), } 2 \text { samples }(\mathrm{M} / \mathrm{F})\end{array}$ & $\begin{array}{l}\text { Separate } \\
\text { samples } \\
(\mathrm{M} / \mathrm{F}) \text {, and } \\
\text { separate } \\
\text { measures } \\
\text { (LTPA/Spo } \\
\text { rts) }\end{array}$ \\
\hline $\begin{array}{l}\text { Packard, C. J., Cavanagh, } \\
\text { J., McLean, J. S., } \\
\text { McConnachie, A., } \\
\text { Messow, C. M., Batty, G. } \\
\text { D., Burns, H., Deans, K. } \\
\text { A., Sattar, N., Shiels, P. }\end{array}$ & 1 & $\begin{array}{l}6 \text { constructs (walking, cycling, gardening, } \\
\text { housework, do-it-yourself projects, hours } \\
\text { of vigorous physical activity engagement) }\end{array}$ & $\begin{array}{l}\text { Separate } \\
\text { measures }\end{array}$ \\
\hline
\end{tabular}


G., Velupillai, Y. N.,

Tannahill, C., \& Millar,

K. (2012)

Read, S., Aunola, K.,

Feldt, T., Leinonen, R., \& samples

Ruoppila, I. (2005)

Sipos, E., Jeges, S., \&

Skirka, N. (2000)

construct, 2 samples

(M/F)

Separate samples

(M/F)

Szczepanska-Klunder, Z., $\quad 2$

1 construct, 2 samples

Separate

\& Lipowski, M. (2014) samples

(M/F)

Vuori, J.

1 construct, 2 samples

Separate samples

$(\mathrm{M} / \mathrm{F})$

Note. ${ }^{a}$ Number of independent samples reported in study; ${ }^{b}$ Number separate behaviors or measures of constructs reported in each sample; ${ }^{~}$ How effect sizes were treated in the meta-analysis. PA $=$ Physical activity; LTPA = Leisure-time physical activity; $\mathrm{M}=$ Male participants; $\mathrm{F}=$ Female participants. 


\section{Appendix C. Summary Characteristics}

\section{Table C1}

Summary Characteristics and Moderator Coding of Studies Included in Meta-Analysis

\begin{tabular}{|c|c|c|c|c|c|c|c|c|c|c|c|c|c|c|c|}
\hline Study & Year & $N$ & $\begin{array}{c}\text { Study } \\
\text { Number } \\
\text { a }\end{array}$ & $\begin{array}{l}\text { Effect } \\
\text { Size }^{\mathrm{b}}\end{array}$ & $r^{\mathrm{c}}$ & $\mathrm{Age}^{\mathrm{d}}$ & $\begin{array}{c}\text { Sex } \\
(\% \\
\text { female } \\
)\end{array}$ & $\begin{array}{c}\text { Modera } \\
\text { tor } \\
\text { coding }\end{array}$ & & & & & & & \\
\hline & & & & & & & & $\operatorname{Sex}^{\mathrm{e}}$ & $\mathrm{Age}^{\mathrm{f}}$ & $\mathrm{SOC}^{\mathrm{g}}$ & $\mathrm{PA}^{\mathrm{h}}$ & $\underset{i}{\text { Intensity }}$ & $\begin{array}{l}\text { Time } \\
\text { lag }^{\mathrm{j}}\end{array}$ & $\underset{\mathrm{h}}{\text { Design }}$ & $\begin{array}{l}\text { Study } \\
\text { quality }^{\mathrm{i}}\end{array}$ \\
\hline $\begin{array}{l}\text { Ahola, A. J., } \\
\text { Mikkilä, V., } \\
\text { Saraheimo, } \\
\text { M., Wadén, } \\
\text { J., } \\
\text { MäkimaTtila, } \\
\text { S., Forsblom, } \\
\text { C., Freese, } \\
\text { R., \& Groop, } \\
\text { P.-H. } \\
\text { Baxevanos, }\end{array}$ & 2012 & 1104 & 1 & 1 & .098 & $\begin{array}{l}M=45 \\
(S D=12)\end{array}$ & $66 \%$ & MIX & MIX & $\begin{array}{c}13 \\
\text { Item }\end{array}$ & SCL & MVG & N/A & CORR & QUE \\
\hline $\begin{array}{l}\text { K., } \\
\text { Topitsoglou, } \\
\text { V., Menexes, } \\
\text { G., \& Kalfas, } \\
\text { S. }\end{array}$ & 2017 & 531 & 2 & 2 & 0.08 & $\begin{array}{l}M=13.5 \\
\text { (range }=13- \\
16)\end{array}$ & $46.9 \%$ & MIX & $\begin{array}{c}Y N \\
G\end{array}$ & $\begin{array}{c}13 \\
\text { Item }\end{array}$ & QUE & GEN & N/A & CORR & QUE \\
\hline $\begin{array}{l}\text { Bronikowski, } \\
\text { M. }\end{array}$ & 2010 & 84 & 3 & 3 & 0.058 & $M_{\text {boys }}=$ & $46 \%$ & MIX & $\begin{array}{c}\text { YN } \\
\text { G }\end{array}$ & $\begin{array}{c}13 \\
\text { Item }\end{array}$ & SCL & MVG & N/A & CORR & QUE \\
\hline
\end{tabular}


$13.25(S D=$

0.40) $M_{\text {girls }}=$

$13.22(S D=$

0.29 )

\section{Bronikowski,}

M.,

Laudanska-

Krzeminska

I., Tomczak,

M., \&

Morina, B.

Chu, J. J.,

Khan, M. H.

Jahn, H. J., \&

Kraemer, A.

Edwards, S. 2002

Endo, S.,

Kanou, H., \& 2012716

Oishi, K.

Endo, S.,

Oishi, K.

Ericson, H., $2018 \quad 32$

Skoog, T.,

Johansson,

M., \&

$M=14.41$

$(S D=1.05$,

range $=13$ 16)

61)

$M=19.4$ 37)
48.8\% MIX $\quad$ YN 13

QUE MVG N/A CORR QUE

$M=20.8 \quad 47.9 \% \quad \mathrm{YN}$

47.9\% MIX $\quad$ G

QUE GEN N/A CORR QUE

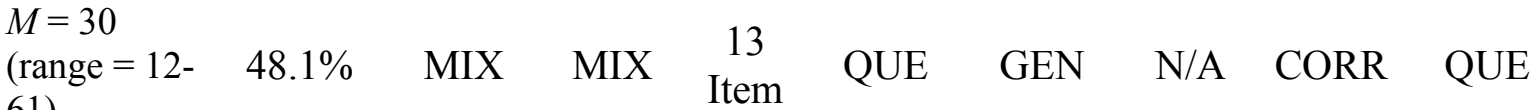

$(S D=1.4, \quad 56 \% \quad$ MIX $\quad$ YN $13 \quad$ QUE $\quad$ MVG $\quad$ N/A $\quad$ CORR QUE

$M=66.9 \quad 0 \% \quad$ MALE OLD $\quad<13$

$S D=4.0) \quad 0 \% \quad$ MALE $\quad$ OLD Items $\quad$ QUE $\quad$ GEN N/A CORR N/A

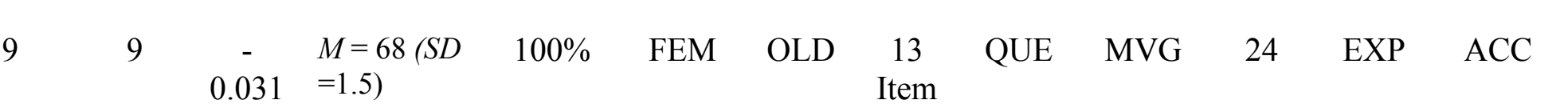


Wåhlin-

Larsson B.

Floyd, A. R. $2008 \quad 56 \quad 10 \quad 10 \quad 0.119 \begin{aligned} & \begin{array}{l}M=6412, \\ \text { range }=41- \\ 84)\end{array} \\ & 53.4 \%\end{aligned} \quad$ MIX $\quad$ OLD $\begin{gathered}29 \\ \text { Item }\end{gathered}$ SCL $\quad$ MIX $\quad$ N/A CORR ACC

Gwiaździńsk

i, P., Fedyk,

O.,

Krawczyk,

2017

16

11

110.577 No $M / S D$

age given

$53.3 \% \quad$ MIX $\quad$ MIX $\begin{gathered}29 \\ \text { Item }\end{gathered}$

QUE LIGHT N/A CORR QUE

M., \&

M.

Hansen Ã.

M.,

Grynderup,

M. B.,

Rugulies, R.,

Conway, $\mathrm{P}$.

M., Garde,

20183288

12

A. H., Török,

$M=47$

E.,

Mikkelsen,

E. G.,

Persson, R.,

Hogh, A.

Hansen Ã.

$2018 \quad 1605$

12

13
$0.141 \quad M=47$
(Range $=$
31-61)

$69.3 \%$

MIX

69.3\% MIX OLD $\begin{gathered}<13 \\ \text { Items }\end{gathered}$ QUE MIX N/A CORR QUE

M.,

Grynderup,

M. B.,

Rugulies, R., 
Conway, $\mathrm{P}$.

M., Garde,

A. H., Török,

E.,

Mikkelsen,

E. G.,

Persson, R.

Hogh, A.

Hassmen, P.,

Koivula, N.,

\& Uutela, A.

13

Holmberg,

S., Thelin,

A., \&

$2004 \quad 554 \quad 14$

Stiernström,

E. L.

Holmberg,

S., Thelin,

A., \&

$2004 \quad 1038$

14

$M_{\mathrm{FEM}}=45.4$
$(S D=11.3)$

Stiernström,

E. L.

Holmberg,

S., Thelin,

A., \&

$2004 \quad 260$

14

17

Stiernström,

E. L.

Jörgensen, S., $2017 \quad 119$

Ginis, K. A.,

Iwarsson, S.,

$15 \quad 18 \quad-\quad M=63$

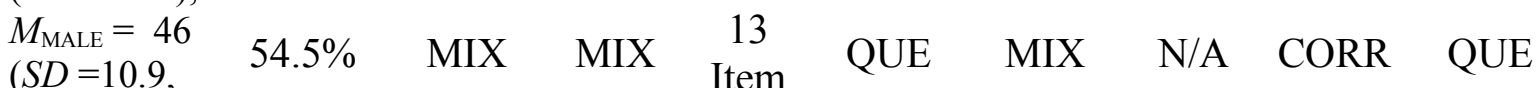
range $=25$

64)

$M=50.3$

$(S D=6$,

range 39-62)

0\% MALE OLD $\begin{gathered}29 \\ \text { Item }\end{gathered}$ QUE $\quad$ MIX N/A $\quad$ CORR QUE

$M=50.3$

$(S D=6$,

range 39-62)

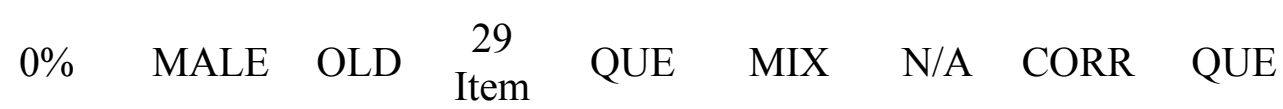

$(S D=6$,

range 39-62)

$0 \%$ MALE $\quad$ OLD $\begin{gathered}29 \\ \text { Item }\end{gathered}$ QUE $\quad$ MVG $\quad$ N/A $\quad$ CORR QUE

29.2\% MIX OLD $13 \quad$ SCL $\quad$ MIX N/A CORR QUE Item 
\& Lexell, J.

Kekäläinen,

T., Kokko,

K., Sipilä, S.,

\& Walker, S.

Baseline-3

months

2018

(Control Vs.

Resistance

training once

a week)

Kekäläinen,

T., Kokko,

K., Sipilä, S.,

\& Walker, $S$.

Baseline-3

months

(Control Vs.

Resistance

training $3 \mathrm{x}$ a

week)

Kekäläinen,

T., Kokko,

K., Sipilä, S.,

\& Walker, $\mathrm{S}$.
$0.059 \begin{aligned} & \text { years (range } \\ & =50-89)\end{aligned}$

$M_{C G}=68.3 \quad \mathrm{CG}=$

$(S D=2.3) \quad 47 \%$

$M_{\mathrm{RT} 1}=68.9 \quad \mathrm{RT} 1=$

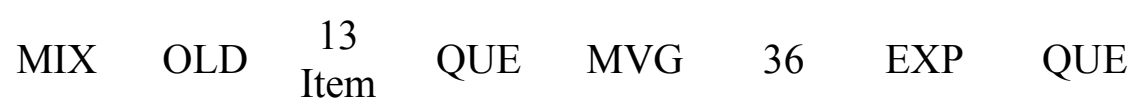

$M_{\mathrm{CG}}=68.3 \quad \mathrm{CG}=$ 2018

$45 \quad 16$

41

16

21

0.149

$M_{\mathrm{RT} 3}=69$

$(S D=3.3)$

$\mathrm{CG}$

\section{(2.3) $\quad 47 \%$}

$\mathrm{RT} 3=$

$57.1 \%$

MIX OLD $\quad 13$

QUE MVG

36

EXP QUE

$\begin{array}{lllllll}\text { MIX OLD } & 13 & \text { QUE } & \text { MVG } & 36 & \text { EXP } & \text { QUE }\end{array}$

Item

Q

$M_{\mathrm{RT1}}=68.9 \quad \mathrm{RT} 1=$

$(S D=2.7) \quad 53.8 \%$ 
Baseline-6

months

(Control vs.

Resistance

training once

a week)

Kekäläinen,

T., Kokko,

K., Sipilä, S.,

\& Walker, S.

Baseline- 6

months

(Control vs.

Resistance

training $3 \mathrm{x}$ a

week)

Kohut, M.

L., Lee, W.,

Martin, A.,

Arnston, B.,

Russell, D.

W.,

2005

Ekkekakis,

P., Yoon, K.

J., Bishop A.,

\& Cunnick $\mathrm{J}$.

E.

Kohut, M.

L., McCann,

\begin{tabular}{|c|c|c|c|c|c|c|c|c|c|c|c|c|c|}
\hline 2018 & 45 & 16 & 22 & 0.054 & $\begin{array}{l}M_{\mathrm{CG}}=68.3 \\
(S D=2.3) \\
M_{\mathrm{RT} 3}=69 \\
(S D=3.3)\end{array}$ & $\begin{array}{c}\mathrm{CG}= \\
47 \% \\
\mathrm{RT} 3= \\
57.1 \%\end{array}$ & MIX & OLD & $\begin{array}{c}13 \\
\text { Item }\end{array}$ & QUE & MVG & 36 & EXP \\
\hline
\end{tabular}


D. A.,

Russell, D.

W.,

Konopka, D.

N., Cunnick,

J. E., Franke,

W. D.,

Castillo, M.

C., Reighard,

A. E., \&

Vanderah, E.

(Flexibility/S

trength

training)

Kohut, M.

L., McCann,

D. A.,

Russell, D.

W.,

Konopka, D.

N., Cunnick,

J. E., Franke,

W. D.,

$2006 \quad 40$

40

19

25

$0.794 \quad M=69.8$

$60.4 \% \quad$ MIX OLD 13

QUE MVG

40

EXP

QUE

Castillo, M.

C., Reighard,

A. E., \&

Vanderah, E.

(Cardio

training)

Kouvonen,

$2008 \quad 5827$

20

26

$0.175 \quad M=39.4$

$(S D=10.4$,

$0 \%$

MALE MIX

13

QUE LIGHT Item 
Väänänen,

A., Woods,

S. A.,

Heponiemi,

T., Koskinen,

range $=18$

A., \&

Toppinen-

Tanner, S.

Kuuppelomäki

, M. \&

$2003 \quad 284$

65)

Utriainen, $\mathrm{P}$

Lei, Y.
Lundstrom,
S., Jormfeld,

S., Jormfeldt,

H.,

Ahlstrom, B

2019

H., \&

Skärsäter, I.

Malabo, A.,

van Eeden,

C., \&

$2007 \quad 293$

Wissing,

2019195

M.P.

Malinauskas, $2018 \quad 885$

R.,

Malinauskien

$\begin{aligned} & \\ & \\ & 45.44(S D \\ & 8.61)\end{aligned}$$$
(S D=13.2
$$

range $=22$ -

83)

$M_{\mathrm{MALE}}$
45.44
$8.61)$
$M_{\mathrm{FEM}}$

$50.46(S D=$

40\% MIX OLD $\begin{gathered}13 \\ \text { Item }\end{gathered}$ SCL GEN N/A CORR QUE

11.63 , range

$=25-74$ )

45.1\% MIX MIX $\begin{gathered}13 \\ \text { Item }\end{gathered}$ QUE GEN N/A CORR ACC

Item

SCL

$(S D=4.20)$

$48.4 \%$

MIX

YN

29

SCL MIX N/A CORR QUE

$25 \quad 31$

$0.01 \quad$ Range $=$

14-15

\section{$0 \%$}

MALE
YN 13 QUE MIX

$\begin{array}{cc}\mathrm{YN} & 13 \\ \mathrm{G} & \text { Item }\end{array}$


è, V., \&

Malinauskas,

M.

Malinauskien

è, V.,

Leišytè, P.,

\&

$2009 \quad 370$

$26 \quad 32$

$\begin{array}{ll}0.19 & \begin{array}{l}\text { Range }= \\ 24-70\end{array}\end{array}$

Malinauskas,

$\mathrm{R}$.

Matsuo, M.

\& Suzuki, E. $2017 \quad 707$

Mayer, J., \&

Thiel, A.

$2014 \quad 142$

$27 \quad 33$

$.016 \quad M=33.9$

$90.1 \%$

FEM MIX $\quad \begin{gathered}13 \\ \text { Item }\end{gathered}$

QUE GEN N/A CORR QUE

Mayer, J., \&

$$
2014 \quad 1305
$$

29

$M=22.85$

Thiel, A.

Moksnes,

U.K., Løhre,

A \&

$2013 \quad 1026$

$30 \quad 36$

36

$0.19 \begin{aligned} & M=15(S D \\ & =1.62)\end{aligned}$

$51.2 \%$

MALE $\quad$ YN $<13$

QUE MIX N/A CORR QUE

Espnes, G.A

Myers, V.,

Drory, Y., \&

2011643

Gerber, Y.

Myrin, B. \&

Lagerstrom,

$\begin{array}{llll}2006 & 187 & 32 & 38\end{array}$

M. (Males

who engage

in LTPA and 
those who do

not)

Myrin, B. \&

Lagerstrom,

M. (Females

who engage

in LTPA and

those who do

not)

Myrin, B. \&

Lagerstrom,

M. (Males

who take

sports lesson

and play

competitivel

$y$ vs. those

who do not)

Myrin, B. \&

Lagerstrom,

M. (Females

who take

sports lesson

and play

2006

competitivel

y vs. those

who do not)

Nagata, S.

Nakamura,
$2006 \quad 196$

196

33

41

$0.156 \begin{aligned} & \text { Range }= \\ & 14-15\end{aligned}$

$100 \% \quad$ FE

$M=38.81$

$2018 \quad 155$

2003

101

$\begin{array}{llll}34 & 42 & 0.255 & \begin{array}{l}M=38.81 \\ (S D= \\ 14.86)\end{array} \\ 35 & 43 & 0.174 & M=43.0\end{array}$

\begin{tabular}{|c|c|c|c|c|c|c|c|c|}
\hline $61.9 \%$ & MIX & MIX & $\begin{array}{c}13 \\
\text { Item }\end{array}$ & SCL & MVG & N/A & CORR & QUE \\
\hline $0 \%$ & MALE & MIX & 29 & QUE & GEN & N/A & CORR & QUE \\
\hline
\end{tabular}


H.,

Matsuzaki,

I., Sasahara,

S., Hatta, K.,

Nagase, H.,

Oshita, Y.,

Ogawa, Y.,

Nobukuni, Y.

$$
(S D=12.0 \quad \text { Item }
$$

Kambayashi,

Y., \& Ogino

$\mathrm{K}$.

Nøst, T. H.,

Steinsbekk,

A., Bratås

$2018 \quad 12$

O., \&

$\begin{array}{ccc}0.078 & M=52.7 \\ 44 & 7 & (S D=11.7)\end{array}$

Grønning, K.

Olesen, K.,

Jensen, $\mathrm{T}$.

M., Diaz, L.

J., Moller,

$2017 \quad 115$

A., Willaing,

I., \&

Lyssenko, V.

Oztekin, C.

\& Tezer, E.

$2009 \quad 364$

$38 \quad 46$

$M=22.1$

Packard, C. $2012 \quad 636$

39

J., Cavanagh,

$(S D=1.62$,

range $=18$ -

30)

$M=60.7$

$(S D=9.6)$

$58 \%$

MIX OLD $\begin{gathered}13 \\ \text { Item }\end{gathered}$

QUE MVG

N/A CORR QUE

$M=51.61$

$0.102 \quad(S D=8.25)$

$44.9 \%$

$\begin{array}{cccccccc}\text { MIX } & \text { YN } & 13 & \text { SCL } & \text { MVG } & \text { N/A } & \text { CORR } & \text { QUE }\end{array}$

$50.9 \%$ MIX OLD 29 QUE LIGHT N/A CORR ACC

Item


J., McLean,

J. S.,

McConnachi

e, A.,

Messow, C.

M., Batty, G.

D., Burns,

H., Deans, K.

A., Sattar,

N., Shiels, P.

G.,

Velupillai, Y.

N.,

Tannahill,

C., \& Millar,

K. (Walking)

Packard, C.

J., Cavanagh,

J., McLean,

J. S.,

McConnachi

e, A.,

Messow, C.

M., Batty, G.

D., Burns,

H., Deans, K.

A., Sattar,

N., Shiels, P.

G.,

Velupillai, Y.

N.,
$2012 \quad 285$

39

48

0.023

$M=51.61$

$50.9 \%$

MIX

OLD

29

QUE

MVG

N/A

CORR ACC

\section{Item}


Tannahill,

C., \& Millar,

K. (Cycling)

Packard, C.

J., Cavanagh,

J., McLean,

J. S.,

McConnachi

e, A.,

Messow, C.

M., Batty, G.

D., Burns,

H., Deans, K. $2012 \quad 48$

A., Sattar,

N., Shiels, P.

G.,

Velupillai, Y.

N.,

Tannahill,

C., \& Millar,

$\mathrm{K}$.

(Gardening)

Packard, C.

J., Cavanagh,

$2012 \quad 642$

J., McLean,

J. S.,

McConnachi

e, A.,

Messow, C.

M., Batty, G.

D., Burns,

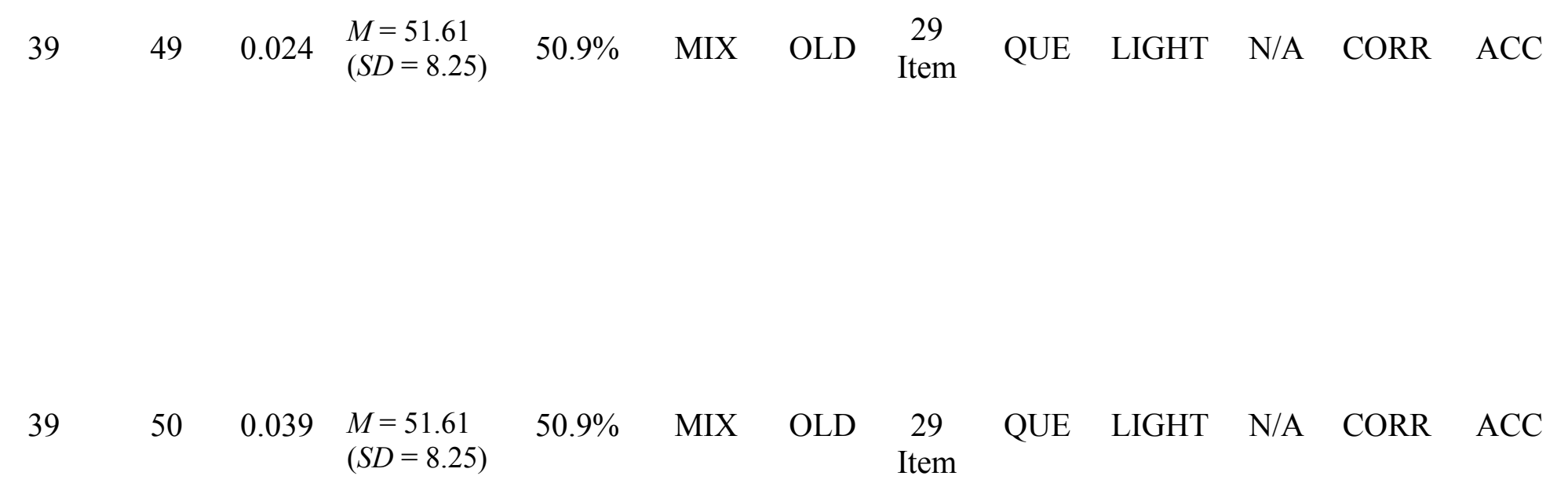


H., Deans, K.

A., Sattar,

N., Shiels, P.

G.,

Velupillai, Y.

N.,

Tannahill,

C., \& Millar,

$\mathrm{K}$.

(Housework)

Packard, C.

J., Cavanagh,

J., McLean,

J. S.,

McConnachi

e, A.,

Messow, C.

M., Batty, G.

D., Burns,

H., Deans, K. 2012

A., Sattar,

G.,

Velupillai, Y.

N.,

Tannahill,

C., \& Millar,

K. (Do-it-

yourself

projects)

Packard, C. 
J., Cavanagh,

J., McLean,

J. S.,

McConnachi

e, A.,

Messow, C.

M., Batty, G.

D., Burns,

H., Deans, K.

A., Sattar,

$0.089 \quad(S D=8.25)$

Item

N., Shiels, P.

G.,

Velupillai, Y.

N.,

Tannahill,

C., \& Millar,

K. (Hours of

Mod-vig PA)

Pakkala, I.,

Read, S.,

Sipilä, S.,

Portegijs, E.,

Kallinen, M.,

Heinonen,

$2012-46$

A., Alen, M.,

Kiviranta, I.,

\& Rantanen,

T.

Peker, K.,

Bermek, G.

\& Uysal, O.

$2012 \quad 566$

54

$0.374 \begin{array}{ll}M=21.12 \\ (S D=1.60)\end{array}$

$55 \%$

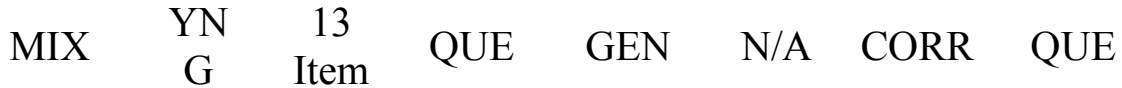


Poppius, E.,

Tenkanen,

L., Kalimo,

19994405

R., \&

$42 \quad 55 \quad 0.087 \begin{aligned} & \begin{array}{l}\text { Range }= \\ 40-55\end{array}\end{aligned}$

$0 \% \quad$ MALE OLD $\quad \begin{gathered}13 \\ \text { Item }\end{gathered}$

SCL MIX N/A CORR QUE

Heinsalmi, P.

Read, S.,

Aunola, K.,

Feldt, T.,

Leinonen, R., $2005 \quad 188 \quad 43 \quad 56 \quad 0.09 \quad \begin{aligned} & \text { Range }= \\ & 65-69\end{aligned}$

\& Ruoppila,

I. (Female

sample)

Read, S.,

Aunola, K.,

Feldt, T.,

Leinonen, R.,

I. (Male

sample)

Santhouse,

R.

$2009 \quad 163$

Savolainen,

20094096$$
\text { 65-69 }
$$

FEM OLD $\begin{gathered}13 \\ \text { Item }\end{gathered}$ QUE GEN N/A CORR QUE

$100 \%$

J.,

Suominen-

Taipale, A.,

Uutela, A.,

Aromaa, A.,

Harkanen,

T., \& 
Knuuttila, M.

Silarova, B.,

Nagyova, I.,

Rosenberger,

J.,

Studencan,

M.

Ondusova,

D.,

Reijneveld,

S. A., \& Van

Dijk, J. P.

Sipos, E.,

Jeges, S., \&

Toth, A.

(Male

587

sample)

Sipos, E.,

Jeges, S., \&

Toth, A.

(Female

sample)

Skirka, N.

(Male

sample)

Skirka, N.

(Female

sample)

Sollerhed, A

C., Ejlertsson

G., \&

$2015 \quad 504$

2000

$2005 \quad 297$

$2014 \quad 179$

47

60

$S D=6.54$

range $=39$

73)

$19 \%$

MALE OLD $\begin{gathered}13 \\ \text { Item }\end{gathered}$ QUE GEN N/A CORR QUE

$\begin{array}{llccccccc}0 \% & \text { MALE } & \text { YN } & 13 & \text { QUE } & \text { MIX } & \text { N/A } & \text { CORR } & \text { QUE }\end{array}$

$2000 \quad 136$

$52-65$

(2)

(6)

519

\begin{tabular}{|c|c|c|c|c|c|c|c|c|c|}
\hline $\begin{array}{l}\text { Range }= \\
6-17\end{array}$ & $0 \%$ & MALE & $\begin{array}{c}\mathrm{YN} \\
\mathrm{G}\end{array}$ & $\begin{array}{c}13 \\
\text { Item }\end{array}$ & QUE & MIX & $\mathrm{N} / \mathrm{A}$ & CORR & QUE \\
\hline $\begin{array}{l}\text { ange }= \\
6-17\end{array}$ & $100 \%$ & FEM & $\begin{array}{c}\text { YN } \\
\text { G }\end{array}$ & $\begin{array}{c}13 \\
\text { Item }\end{array}$ & QUE & MIX & $\mathrm{N} / \mathrm{A}$ & CORR & QUE \\
\hline $\begin{array}{l}\text { lange }= \\
7-24\end{array}$ & $0 \%$ & MALE & $\begin{array}{c}\text { YN } \\
\text { G }\end{array}$ & $\begin{array}{c}29 \\
\text { Item }\end{array}$ & QUE & MIX & $\mathrm{N} / \mathrm{A}$ & CORR & QUE \\
\hline $\begin{array}{l}\operatorname{lnge}= \\
-24\end{array}$ & $100 \%$ & FEM & $\begin{array}{c}\text { YN } \\
\text { G }\end{array}$ & $\begin{array}{c}29 \\
\text { Item }\end{array}$ & QUE & MIX & $\mathrm{N} / \mathrm{A}$ & CORR & QUE \\
\hline $\begin{array}{l}\text { Range }=16- \\
9\end{array}$ & $43.5 \%$ & MIX & $\begin{array}{c}\text { YN } \\
\text { G }\end{array}$ & $\begin{array}{c}13 \\
\text { Item }\end{array}$ & QUE & MVG & $\mathrm{N} / \mathrm{A}$ & CORR & QUE \\
\hline
\end{tabular}


Apitzsch E.

Suominen,

S., Gould, R.

Ahvenainen,

J., Vahtera,

J., Uutela,

20052196

53

$660.117 \quad \begin{gathered}\text { Range } \\ 15-64\end{gathered}$

49.2\% MIX MIX $\begin{gathered}29 \\ \text { Item }\end{gathered}$

QUE GEN N/A CORR QUE

A., \&

Koskenvuo,

M.

Super, S.,

Hermens, N.,

Verkooijen,

2018186

54

67

$0.045 \quad M=14.68$

$\begin{array}{cccc}20.3 \% & \text { MALE } & \text { YN } & 13 \\ \text { G } & \text { Item }\end{array}$

QUE MVG N/A CORR QUE

K., \&

Koelen, M.

Szczepanska-

Klunder, Z.,

\& Lipowski,

M.

$2014 \quad 242$

242

$55 \quad 68$

$.06 \quad \begin{aligned} & M=40.05 \\ & (S D=9.09)\end{aligned}$

$0 \%$ MALE MIX

29

QUE GEN N/A CORR QUE

(Male

sample)

Szczepanska-

Klunder, Z.,

\& Lipowski

M.

$2014 \quad 235$

(Female

sample)

Vuori, J.

(Male

$1994 \quad 361$

$57 \quad M=36(S D$

sample)

$1994 \quad 361$

$58 \quad 71$

$0.07=2.8$, range

$=31-44)$

$0 \%$ MALE MIX

29

QUE GEN N/A CORR QUE

Vuori, J.

$1994 \quad 345$

$0.13 M=36(S D$

$=2.8$, range

$100 \%$

FEM MIX

29 QUE GEN N/A CORR QUE 
sample)

Wiesmann

U. \&

Hannich H.

J.

Ziolkowski,

A.,

Zubrzycki, I.,

Blachnio, A., 2016273

Drobnik, P.,

Zaranska, B.,

\& Moska, W.

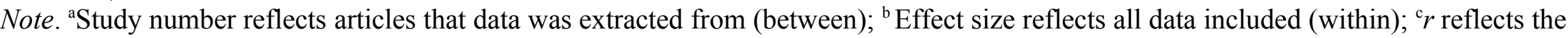

sample-weighted correlation of the effect size between sense of coherence and physical activity engagement; ${ }^{\mathrm{d}}$ Age expressed in years

unless otherwise stated; ${ }^{\text {eSex }}$ moderator coding, samples comprising $>75 \%$ female coded as FEM, samples between $26-74 \%$ female coded as MIX, and samples comprising $<25 \%$ female coded as MALE; ${ }^{\mathrm{f}}$ Age moderator coding, samples with mean age of 40 years or older, SDs less than 10 coded OLD, samples with very large age range from young to old were coded MIX, samples with mean age younger than 40, SDs less than 10 were coded YNG; ' scale of physical activity engagement coded as SCL, studies that utilized physical activity questions (not a full scale) or split groups into

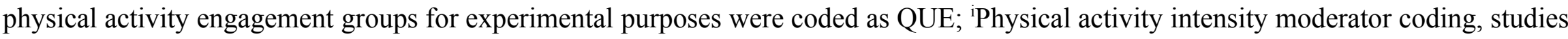
which included a general measure of physical activity engagement without intensity accounted for were coded as GEN, studies which included only a measurement of light intensity physical activity were coded LIGHT, studies which included only a measurement of 
moderate-vigorous intensity physical activity were coded MVG, studies which effect sizes were derived from comparing multiple physical activity engagement intensities were coded MIX; ${ }^{\mathrm{g}}$ Time lag moderator, continuous, N/A = Data not available or coding not possible; ${ }^{\mathrm{h}}$ Study design moderator, if effect size was derived from cross-sectional correlation or baseline data coded as CORR, if the effect size was

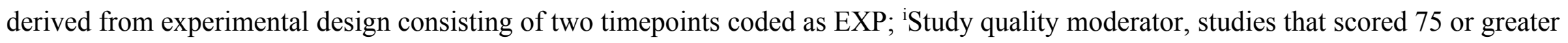
on the Quality Assessment Checklist for Survey Studies in Psychology (QSS-P) were coded ACC, those that scored below 75 were coded QUE. 


\section{Appendix D. Studies Included in the Meta-Analysis}

Ahola, A. J., Mikkilä, V., Saraheimo, M., Wadén, J., MäkimaTtila, S., Forsblom, C., Freese, R., \& Groop, P.-H. (2012). Sense of coherence, food selection and leisure time physical activity in type 1 diabetes. Scandinavian Journal of Public Health, 40(7), 621-628. https://doi.org/10.1177/1403494812460346

Baxevanos, K., Topitsoglou, V., Menexes, G., \& Kalfas, S. (2017). Psychosocial factors and traumatic dental injuries among adolescents. Community Dentistry and Oral Epidemiology, 45(5), 449-457. https://doi.org/10.1111/cdoe.12309

Bronikowski, M. (2010). Is sense of coherence needed to keep youth physically active? Medicina Dello Sport, 63(4), 465-483.

Bronikowski, M., Laudanska-Krzeminska, I., Tomczak, M., \& Morina, B. (2017). Sense of coherence, physical activity and its associations with gender and age among Kosovar adolescents: A cross-sectional study. The Journal of Sports Medicine and Physical Fitness, 57(7-8), 1023-1032. DOI: 10.23736/s0022-4707.16.06394-5

Chu, J. J., Khan, M. H., Jahn, H. J., \& Kraemer, A. (2016). Sense of coherence and associated factors among university students in China: Cross-sectional evidence. BMC Public Health, 16(1), 336. https://doi.org/10.1186/s12889-016-3003-3

Edwards, S. (2002). Physical exercise and psychological wellness. International Journal of Mental Health Promotion, 4(2), 40-46. https://doi.org/10.1080/14623730.2002.9721860

Endo, S., Kanou, H., \& Oishi, K. (2012). Sports activities and sense of coherence (SOC) among college students. International Journal of Sport and Health Science, 10(0), 1-11. https://doi.org/10.5432/ijshs.201114 
Endo, S., Kanou, H., \& Oishi, K. (2012, May). Relationship between the habit of exercise and sense of coherence among retired males in Japan. Medicine and Science in Sports and Exercise; (Conference Abstract, Vol. 44, pp. 812-813).

Ericson, H., Skoog, T., Johansson, M., \& Wåhlin-Larsson, B. (2018). Resistance training is linked to heightened positive motivational state and lower negative affect among healthy women aged 65-70. Journal of Women and Aging, 30(5), 366-381. https://doi.org/10.1080/08952841.2017.1301720

Floyd, A. R. (2007). Sense of coherence and quality of life in lung cancer: Potential psychological, behavioral and biological mediators. [Doctoral dissertation; University of Louisville].

Gwiaździński, P., Fedyk, O., Krawczyk, M., \& Szymański, M. (2017). Practicing hatha-yoga, sense of coherence and sense of agency. Neurophenomenological approach. Psychiatria Danubina, 29(Suppl. 3), 530-535.

Hansen Ã. M., Grynderup, M. B., Rugulies, R., Conway, P. M., Garde, A. H., Török, E., Mikkelsen, E. G., Persson, R., Hogh, A. (2018). A cohort study on self-reported role stressors at work and poor sleep: Does sense of coherence moderate or mediate the associations? International Archives of Occupational and Environmental Health, 91, 445456. https://doi.org/10.1007/s00420-018-1294-7

Hassmen, P., Koivula, N., \& Uutela, A. (2000). Physical exercise and psychological well-being: A population study in Finland. Preventive Medicine, 30(1), 17-25. https://doi.org/10.1006/ pmed.1999.0597 
Holmberg, S., Thelin, A., \& Stiernström, E. L. (2004). Relationship of sense of coherence to other psychosocial indices. European Journal of Psychological Assessment, 20(4), 227236. https://doi.org/10.1027/1015-5759.20.4.227

Jörgensen, S., Ginis, K. A., Iwarsson, S., \& Lexell, J. (2017). Depressive symptoms among older adults with long-term spinal cord injury: Associations with secondary health conditions, sense of coherence, coping strategies and physical activity. Journal of Rehabilitation Medicine, 49(8), 644-651. https://doi.org/10.2340/16501977-2259

Kekäläinen, T., Kokko, K., Sipilä, S., \& Walker, S. (2018). Effects of a 9-month resistance training intervention on quality of life, sense of coherence, and depressive symptoms in older adults: Randomized controlled trial. Quality of Life Research, 27(2), 455-465. https://doi.org/10.1007/s11136-017-1733-z

Kohut, M. L., Lee, W., Martin, A., Arnston, B., Russell, D. W., Ekkekakis, P., Yoon, J., Bishop, A., \& Cunnick, J. E. (2005). The exercise-induced enhancement of influenza immunity is mediated in part by improvements in psychosocial factors in older adults. Brain, Behavior, and Immunity, 19(4), 357-366. https://doi.org/10.1016/j.bbi.2004.12.002

Kohut, M. L., McCann, D. A., Russell, D. W., Konopka, D. N., Cunnick, J. E., Franke, W. D., Castillo, A. E., Reighard, A. E., \& Vanderah, E. (2006). Aerobic exercise, but not flexibility/resistance exercise, reduces serum IL-18, CRP, and IL-6 independent of $\beta$ blockers, BMI, and psychosocial factors in older adults. Brain, Behavior, and Immunity, 20(3), 201-209. https://doi.org/10.1016/j.bbi.2005.12.002

Kouvonen, A. M., Väänänen, A., Woods, S. A., Heponiemi, T., Koskinen, A., \& ToppinenTanner, S. (2008). Sense of coherence and diabetes: A prospective occupational cohort study. BMC Public Health, 8(1), 46. https://doi.org/10.1186/1471-2458-8-46 
Kuuppelomäki, M., \& Utriainen, P. (2003). A 3-year follow-up study of health care students' sense of coherence and related smoking, drinking and physical exercise factors.

International Journal of Nursing Studies, 40(4), 383-388. https://doi.org/10.1016/S00207489(02)00103-7

Lei, Y. (2019). The effects of a strengths-based intervention based on salutogenic model on selfcare behaviors and sense of coherence in older adults with type 2 diabetes. [Doctoral dissertation; The Chinese University of Hong Kong].

Lundström, S., Jormfeldt, H., Ahlström, B. H., \& Skärsäter, I. (2019). Health-related lifestyle and perceived health among people with severe mental illness: Gender differences and degree of sense of coherence. Archives of Psychiatric Nursing, 33(2), 182-188. https://doi.org/10.1016/j.apnu.2018.12.002

Malebo, A., Van Eeden, C., \& Wissing, M. P. (2007). Sport participation, psychological wellbeing, and psychosocial development in a group of young black adults. South African Journal of Psychology, 37(1), 188-206. https://doi.org/10.1177/008124630703700113

Malinauskas, R., Malinauskiene, V., \& Malinauskas, M. (2018). Lifetime traumatic experiences and leisure physical inactivity among adolescent boys. Puerto Rico Health Sciences Journal, 37(1), 32-38.

Malinauskienė, V., Leišytė, P., \& Malinauskas, R. (2009). Psychosocial job characteristics, social support, and sense of coherence as determinants of mental health among nurses. Medicina, 45(11), 910. https://doi.org/10.3390/medicina45110117

Matsuo, M., \& Suzuki, E. (2017). Factors related to sense of coherence (SOC) among nurses in Japan. Worldwide Nursing Conference (WNC, 2017). https://doi.org/10.5176/23154330_WNC17.100 
Mayer, J., \& Thiel, A. (2014). Health in elite sports from a salutogenetic perspective: Athletes' sense of coherence. PloS One, 9(7), e102030. https://doi.org/10.1371/journal.pone.0102030

Moksnes, U. K., Løhre, A., \& Espnes, G. A. (2013). The association between sense of coherence and life satisfaction in adolescents. Quality of Life Research, 22(6), 1331-1338. https://doi.org/10.1007/s11136-012-0249-9

Myers, V., Drory, Y., \& Gerber, Y. (2011). Sense of coherence predicts post-myocardial infarction trajectory of leisure time physical activity: A prospective cohort study. $B M C$ Public Health, 11(1), 708. https://doi.org/10.1186/1471-2458-11-708

Myrin, B., \& Lagerström, M. (2006). Health behaviour and sense of coherence among pupils aged 14-15. Scandinavian Journal of Caring Sciences, 20(3), 339-346. https://doi.org/10.1111/j.1471-6712.2006.00413.x

Nagata, S. (2017). Leisure and symptoms of depression: Identification of the role of leisuregenerated resources, physical activity, and sense of coherence. [Doctoral dissertation, Indiana University].

Nakamura, H., Matsuzaki, I., Sasahara, S., Hatta, K., Nagase, H., Oshita, Y., ... \& Ogino, K. (2003). Enhancement of a sense of coherence and natural killer cell activity which occurred in subjects who improved their exercise habits through health education in the workplace. Journal of Occupational Health, 45(5), 278-285.

https://doi.org/10.1539/joh.45.278

Nøst, T. H., Steinsbekk, A., Bratås, O., \& Grønning, K. (2018). Twelve-month effect of chronic pain self-management intervention delivered in an easily accessible primary healthcare 
service-A randomised controlled trial. BMC Health Services Research, 18(1), 1012. https://doi.org/10.1186/s12913-018-3843-x

Olesen, K., Jensen, T. M., Diaz, L. J., Møller, A. C. L., Willaing, I., \& Lyssenko, V. (2017). Sense of Coherence is associated with LDL-cholesterol in patients with type 1 diabetesThe PROLONG-Steno study. Journal of Clinical \& Translational Endocrinology, 8, 1-5. https://doi.org/10.1016/j.jcte.2017.01.003

Öztekin, C., \& Tezer, E. (2009). The role of sense of coherence and physical activity in positive and negative affect of Turkish adolescents. Adolescence: An International Quarterly Devoted to the Physiological, Psychological, Psychiatric, Sociological, and Educational Aspects of the Second Decade of Human Life, 44(174), 421-432.

Packard, C. J., Cavanagh, J., McLean, J. S., McConnachie, A., Messow, C. M., Batty, G. D., ... \& Velupillai, Y. N. (2012). Interaction of personality traits with social deprivation in determining mental wellbeing and health behaviours. Journal of Public Health, 34(4), 615-624. https://doi.org/10.1093/pubmed/fds030

Pakkala, I., Read, S., Sipilä, S., Portegijs, E., Kallinen, M., Heinonen, A., ... \& Rantanen, T. (2012). Effects of intensive strength-power training on sense of coherence among 60-85year-old people with hip fracture: A randomized controlled trial. Aging Clinical and Experimental Research, 24(3), 295-299. https://doi.org/10.1007/BF03325261

Peker, K., Bermek, G., \& Uysal, O. (2012). Factors related to sense of coherence among dental students at Istanbul University. Journal of Dental Education, 76(6), 774-782.

Poppius, E., Tenkanen, L., Kalimo, R., \& Heinsalmi, P. (1999). The sense of coherence, occupation and the risk of coronary heart disease in the Helsinki Heart Study. Social Science and Medicine, 49(1), 109-120. https://doi.org/10.1016/S0277-9536(99)00105-7 
Read, S., Aunola, K., Feldt, T., Leinonen, R., \& Ruoppila, I. (2005). The relationship between generalized resistance resources, sense of coherence, and health among Finnish people aged 65-69. European Psychologist, 10(3), 244-253. https://doi.org/10.1027/10169040.10 .3 .244

Santhouse, R. (2008). Correlates of service utilization and adherence to dietary and exercise modifications in a sample of women before and after bariatric surgery. [Doctoral dissertation, University of Pittsburgh].

Savolainen, J., Suominen-Taipale, A., Uutela, A., Aromaa, A., Härkänen, T., \& Knuuttila, M. (2009). Sense of coherence associates with oral and general health behaviours.

Community Dental Health, 26(4), 197-203.

https://doi.org/10.1922/CDH_2335Savolainen07

Silarova, B., Nagyova, I., Rosenberger, J., Studencan, M., Ondusova, D., Reijneveld, S. A., \& van Dijk, J. P. (2014). Sense of coherence as a predictor of health-related behaviours among patients with coronary heart disease. European Journal of Cardiovascular Nursing, 13(4), 345-356. https://doi.org/10.1177/1474515113497136

Sipos, E., Jeges, S., \& Tóth, Á. (2015). Sport, sense of coherence, and self-esteem among 16 and 17-year-olds. European Journal of Mental Health, 10(1), 62-78. https://doi.org/10.5708/EJMH.10.2015.1.4

Skirka, N. (2000). The relationship of hardiness, sense of coherence, sports participation, and gender to perceived stress and psychological symptoms among college students. [Doctoral dissertation, New York University]. 
Sollerhed, A. C., Ejlertsson, G., \& Apitzsch, E. (2005). Predictors of strong sense of coherence and positive attitudes to physical education in adolescents. Scandinavian Journal of Public Health, 33(5), 334-342. https://doi.org/10.1080/14034940510005833

Suominen, S., Gould, R., Ahvenainen, J., Vahtera, J., Uutela, A., \& Koskenvuo, M. (2005). Sense of coherence and disability pensions. A nationwide, register based prospective population study of 2196 adult Finns. Journal of Epidemiology \& Community Health, 59(6), 455-459. http://dx.doi.org/10.1136/jech.2003.019414

Super, S., Hermens, N., Verkooijen, K., \& Koelen, M. (2018). Examining the relationship between sports participation and youth developmental outcomes for socially vulnerable youth. BMC Public Health, 18(1), 1012. https://doi.org/10.1186/s12889-018-5955-y

Szczepanska-Klunder, Z., \& Lipowski, M. (2014). Sense of coherence as a moderator of healthrelated behavior of physical education teachers. Baltic Journal of Health and Physical Activity, 6(2), 127-134. https://doi.org/10.2478/bjha-2014-0012

Vuori, J. (1994). Pre-employment antecedents of health resources, job factors and health risk behaviour in men and women. Work \& Stress, 8(3), 263-277. https://doi.org/10.1080/02678379408259998

Wiesmann, U., \& Hannich, H. J. (2011). Salutogenic perspectives on health maintenance. GeroPsych, 24(3) 127-135. https://doi.org/10.1024/1662-9647/a000040

Ziolkowski, A., Zubrzycki, I., Blachnio, A., Drobnik, P., Zaranska, B., \& Moska, W. (2016). Influence of sport activity on satisfaction with life and sense of coherence among physically disabled people. Baltic Journal of Health and Physical Activity, 8(4), 109-16. https://doi.org/10.29359/BJHPA.08.4.12 
ppendix E. PRISMA Checklist

\begin{tabular}{|c|c|c|c|}
\hline Section/topic & \# & Checklist item & $\begin{array}{l}\text { Reported } \\
\text { on page \# }\end{array}$ \\
\hline \multicolumn{4}{|l|}{ TITLE } \\
\hline Title & 1 & Identify the report as a systematic review, meta-analysis, or both. & 1 \\
\hline \multicolumn{4}{|l|}{ ABSTRACT } \\
\hline Structured summary & 2 & $\begin{array}{l}\text { Provide a structured summary including, as applicable: background; objectives; data sources; study } \\
\text { eligibility criteria, participants, and interventions; study appraisal and synthesis methods; results; } \\
\text { limitations; conclusions and implications of key findings; systematic review registration number. }\end{array}$ & 2 \\
\hline \multicolumn{4}{|l|}{ INTRODUCTION } \\
\hline Rationale & 3 & Describe the rationale for the review in the context of what is already known. & 7 \\
\hline Objectives & 4 & $\begin{array}{l}\text { Provide an explicit statement of questions being addressed with reference to participants, interventions, } \\
\text { comparisons, outcomes, and study design (PICOS). }\end{array}$ & 8 \\
\hline \multicolumn{4}{|c|}{ " } \\
\hline Protocol and registration & 5 & $\begin{array}{l}\text { Indicate if a review protocol exists, if and where it can be accessed (e.g., Web address), and, if available, } \\
\text { provide registration information including registration number. }\end{array}$ & 1 \\
\hline Information sources & 7 & $\begin{array}{l}\text { Describe all information sources (e.g., databases with dates of coverage, contact with study authors to } \\
\text { identify additional studies) in the search and date last searched. }\end{array}$ & $8-9$ \\
\hline Search & 8 & $\begin{array}{l}\text { Present full electronic search strategy for at least one database, including any limits used, such that it could } \\
\text { be repeated. }\end{array}$ & 8 \\
\hline Study selection & 9 & $\begin{array}{l}\text { State the process for selecting studies (i.e., screening, eligibility, included in systematic review, and, if } \\
\text { applicable, included in the meta-analysis). }\end{array}$ & $9-10$ \\
\hline
\end{tabular}




\begin{tabular}{|c|c|c|c|}
\hline Data collection process & 10 & $\begin{array}{l}\text { Describe method of data extraction from reports (e.g., piloted forms, independently, in duplicate) and any } \\
\text { processes for obtaining and confirming data from investigators. }\end{array}$ & $10-12$ \\
\hline Data items & 11 & $\begin{array}{l}\text { List and define all variables for which data were sought (e.g., PICOS, funding sources) and any } \\
\text { assumptions and simplifications made. }\end{array}$ & 9 \\
\hline $\begin{array}{l}\text { Risk of bias in individual } \\
\text { studies }\end{array}$ & 12 & $\begin{array}{l}\text { Describe methods used for assessing risk of bias of individual studies (including specification of whether } \\
\text { this was done at the study or outcome level), and how this information is to be used in any data synthesis. }\end{array}$ & 14 \\
\hline Summary measures & 13 & State the principal summary measures (e.g., risk ratio, difference in means). & 13 \\
\hline Synthesis of results & 14 & $\begin{array}{l}\text { Describe the methods of handling data and combining results of studies, if done, including measures of } \\
\text { consistency }\left(\text { e.g., } \mathrm{I}^{2}\right) \text { for each meta-analysis. }\end{array}$ & $13-14$ \\
\hline
\end{tabular}




\section{Appendix F. Funnel Plot for Examination of Publication Bias}

\section{Figure E1}

Funnel Plot of Sense of Coherence Effect Size on Physical Activity Engagement (standardized difference in means) Against Study Precision (standard error) for Visual Inspection of Publication Bias

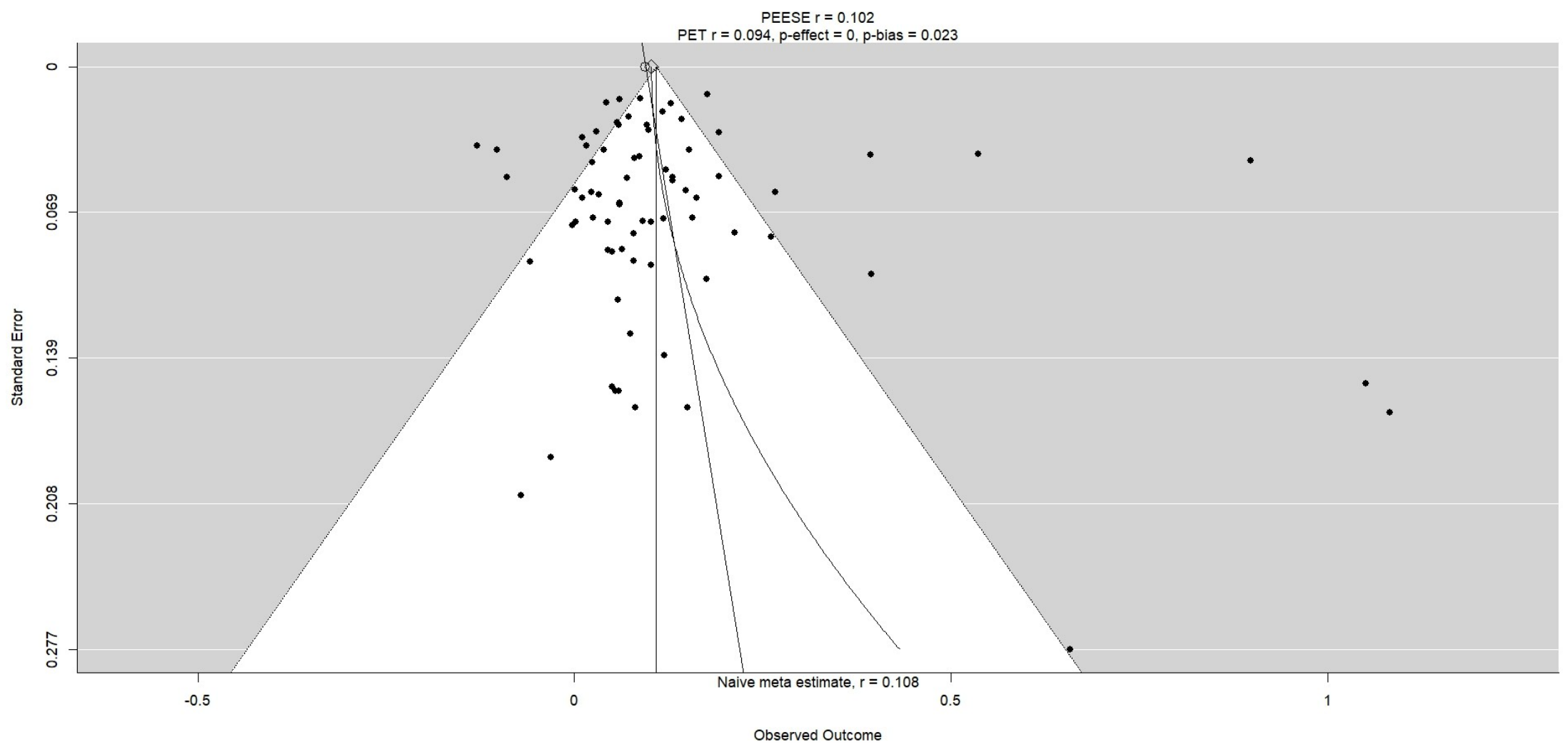

Note. Std diff in means $=$ Standardized difference in mean effect size for each study in the meta-analysis. 


\section{Table 1}

Results of Multi-Level Meta-Analysis of Sense of Coherence and Physical Activity Participation

\begin{tabular}{|c|c|c|c|c|c|c|c|c|c|c|c|c|c|}
\hline \multirow[t]{2}{*}{ Model } & \multirow[t]{2}{*}{$k$} & \multirow[t]{2}{*}{$N$} & \multirow[t]{2}{*}{$r$} & \multicolumn{2}{|c|}{$95 \% \mathrm{CI}$} & \multirow[t]{2}{*}{$\sigma^{2}$ within } & \multirow[t]{2}{*}{$\sigma^{2}$ between } & \multirow[t]{2}{*}{$Q$} & \multirow[t]{2}{*}{$\mathrm{df}$} & \multirow[t]{2}{*}{ AIC } & \multicolumn{3}{|c|}{ Model comparisons } \\
\hline & & & & LL & $\mathrm{UL}$ & & & & & & $\chi^{2}$ & LRT & $p$ \\
\hline Overall & 73 & 49447 & $.142^{* * *}$ & .092 & .193 & .002 & .031 & $778.285^{* * *}$ & 72 & -31.511 & 18.755 & - & - \\
\hline Between-study variance $\left(\sigma^{2}\right)$ only & 73 & 49447 & $.143^{* * *}$ & .092 & .193 & - & .033 & $778.286^{* * *}$ & 72 & -30.335 & 17.167 & 3.176 & .075 \\
\hline Within-study variance $\left(\sigma^{2}\right)$ only & 73 & 49447 & $.125^{* * *}$ & .082 & .168 & .029 & - & $778.285^{* * *}$ & 72 & -22.999 & 13.450 & 10.512 & .0012 \\
\hline
\end{tabular}

Note. $k=$ Number of studies; $N=$ Number of participants; $r=$ Average sample-weighted correlation; $\sigma^{2}$ between = Between-study variance; $\sigma^{2}$

within = Within-study variance; $Q=$ Cochrane's $Q$ statistic; $\mathrm{df}=$ degrees of freedom; AIC $=$ Akaike's Information Criterion; $\chi^{2}=$ Chi-square $($ log

likelihood); LRT = likelihood ratio test; $p=$ Significance level of the LRT.

$* p<.05 * * p<.01 * * * p<.001$ 
Table 2

Moderator Analyses of the Association Between Sense of Coherence (SOC) and Physical Activity Participation (PA)

\begin{tabular}{|c|c|c|c|c|c|c|c|c|c|c|c|c|}
\hline \multirow[t]{3}{*}{ Variable } & \multirow[t]{3}{*}{$k$} & \multirow[t]{3}{*}{$r$} & \multicolumn{2}{|c|}{$95 \% \mathrm{CI}$} & \multirow[t]{3}{*}{$Q$} & \multirow[t]{3}{*}{$\sigma^{2}$ between } & \multirow[t]{3}{*}{$\sigma^{2}$ within } & \multicolumn{5}{|l|}{$\begin{array}{l}{ }^{\text {a Difference }} \\
\text { tests }\end{array}$} \\
\hline & & & \multirow[t]{2}{*}{ LL } & \multirow[t]{2}{*}{ UL } & & & & \multirow[t]{2}{*}{ MD } & \multicolumn{2}{|l|}{$\begin{array}{c}95 \% \\
\text { CI }\end{array}$} & \multirow[t]{2}{*}{$t$} & \multirow[t]{2}{*}{$p$} \\
\hline & & & & & & & & & LL & UL & & \\
\hline \multicolumn{13}{|l|}{ SOC Measures } \\
\hline 29-item & 26 & & .051 & .135 & $67.377^{* * *}$ & 0.002 & 0.002 & $-0.077^{\mathrm{b}}$ & -.172 & .018 & - & 0.12 \\
\hline & & $.093^{* * *}$ & & & & & & & & & 1.527 & 7 \\
\hline 13-item & 40 & & .080 & .259 & $680.719^{* * *}$ & 0.062 & 0.000 & $-0.013^{\mathrm{c}}$ & -.066 & .040 & - & 0.67 \\
\hline & & $.170^{* * *}$ & & & & & & & & & 0.419 & 5 \\
\hline Other & 7 & $.106^{* *}$ & .062 & .150 & $12.633^{*}$ & 0.001 & 0.000 & $0.064^{\mathrm{d}}$ & -.029 & .157 & 1.258 & 0.20 \\
\hline \multicolumn{13}{|l|}{ PA Measures } \\
\hline Previously validated scale & 11 & $.098^{* * *}$ & .071 & .126 & 10.924 & 0.000 & 0.000 & $-0.053^{\mathrm{e}}$ & -.118 & .013 & - & 0.12 \\
\hline Physical activity questions & 62 & $.151^{* * *}$ & .089 & .213 & $766.458^{* * *}$ & 0.040 & 0.002 & & & & 1.595 & 5 \\
\hline \multicolumn{13}{|l|}{ Sample Age (years) } \\
\hline Older $(M>=40, S D<10)$ & 32 & $.149^{*}$ & .035 & .263 & $144.002^{* * *}$ & 0.054 & 0.002 & $0.040^{\mathrm{f}}$ & $\begin{array}{c}- \\
0.083\end{array}$ & $\begin{array}{c}0.16 \\
3\end{array}$ & 0.652 & $\begin{array}{c}0.51 \\
4\end{array}$ \\
\hline Mixed (younger to older) & 18 & $.109^{* * *}$ & .071 & .147 & $80.414^{* * *}$ & 0.002 & 0.002 & $-0.003^{\mathrm{g}}$ & 0155 & $\begin{array}{c}0.14 \\
9\end{array}$ & 0042 & $\begin{array}{c}0.96 \\
6\end{array}$ \\
\hline Younger $(M<40, S D<10)$ & 23 & $.152^{* *}$ & .050 & .254 & $535.808^{* * *}$ & 0.046 & 0.002 & $-0.043^{\mathrm{h}}$ & $\begin{array}{l}- \\
0.146\end{array}$ & 0.05 & $\begin{array}{l}0.042 \\
0781\end{array}$ & 0.43 \\
\hline \multicolumn{13}{|l|}{ Sex } \\
\hline Female $(>=75 \%$ female $)$ & 14 & $.157^{*}$ & .012 & .304 & $302.974^{* * *}$ & 0.050 & 0.004 & $0.003^{\mathrm{i}}$ & $\begin{array}{c}- \\
0.150\end{array}$ & $\begin{array}{c}0.15 \\
6\end{array}$ & 0.036 & $\begin{array}{c}0.97 \\
2\end{array}$ \\
\hline
\end{tabular}




\begin{tabular}{|c|c|c|c|c|c|c|c|c|c|c|c|c|}
\hline Mixed (26\%-74\% female) & 40 & $.155^{* * *}$ & .077 & .234 & $273.674^{* * *}$ & 0.036 & 0.003 & $0.047^{\mathrm{j}}$ & $\begin{array}{c}- \\
0.101\end{array}$ & $\begin{array}{c}0.19 \\
6\end{array}$ & 0.568 & $\begin{array}{c}0.57 \\
0\end{array}$ \\
\hline Male $(>=75 \%$ male $)$ & 19 & $.111^{* *}$ & .040 & .182 & $163.735^{* * *}$ & 0.015 & 0.000 & $0.044^{\mathrm{k}}$ & $\begin{array}{c}- \\
0.057\end{array}$ & $\begin{array}{c}0.14 \\
5\end{array}$ & 0.815 & $\begin{array}{c}0.41 \\
5\end{array}$ \\
\hline \multicolumn{13}{|l|}{ Activity Intensity } \\
\hline General & 25 & $.113^{* * *}$ & .064 & .162 & $127.314^{* * *}$ & 0.005 & 0.005 & $-0.052^{1}$ & -.293 & .189 & 0.324 & $\begin{array}{c}0.74 \\
6\end{array}$ \\
\hline Light & 6 & .165 & -.145 & .475 & $61.251^{* * *}$ & 0.029 & 0.007 & $-0.029^{\mathrm{m}}$ & -.156 & .098 & $\begin{array}{c}- \\
0.423\end{array}$ & $\begin{array}{c}0.67 \\
2\end{array}$ \\
\hline Moderate-Vigorous & 24 & $.142^{*}$ & .018 & .267 & $104.694^{* * *}$ & 0.062 & 0.001 & $-0.051^{\mathrm{n}}$ & -.178 & .076 & $\begin{array}{c}- \\
0.734\end{array}$ & $\begin{array}{c}0.46 \\
3\end{array}$ \\
\hline Mixed & 18 & $.164^{*}$ & .038 & .291 & $463.467^{* * *}$ & 0.054 & 0.000 & $0.023^{\circ}$ & $0 . \overline{241}$ & $\begin{array}{c}0.28 \\
7\end{array}$ & 0.134 & $\begin{array}{c}0.89 \\
3\end{array}$ \\
\hline & & & & & & & & $0.001^{\mathrm{p}}$ & $0 . \overline{263}$ & $\begin{array}{c}0.26 \\
5\end{array}$ & 0.005 & $\begin{array}{c}0.99 \\
6\end{array}$ \\
\hline & & & & & & & & $-0.022^{\mathrm{q}}$ & $\begin{array}{c}- \\
0.188\end{array}$ & $\begin{array}{c}0.14 \\
4\end{array}$ & 0.243 & $\begin{array}{c}0.80 \\
8\end{array}$ \\
\hline \multicolumn{13}{|l|}{ Design } \\
\hline Intervention/Experiment & 9 & .363 & -.152 & .879 & $64.231^{* * *}$ & 0.274 & 0.000 & $-0.238^{r}$ & $\begin{array}{c}- \\
0.677\end{array}$ & $\begin{array}{c}0.20 \\
1\end{array}$ & $\begin{array}{c}- \\
0.902\end{array}$ & $\begin{array}{c}0.36 \\
8\end{array}$ \\
\hline $\begin{array}{l}\text { Correlation } \\
\text { Study Quality }\end{array}$ & 64 & $.125^{* * *}$ & .081 & .169 & $702.273^{* * *}$ & 0.020 & 0.003 & & & & & \\
\hline Acceptable & 11 & .067 & -.033 & .166 & $27.207^{* *}$ & 0.003 & 0.004 & $0.052^{\mathrm{s}}$ & $\begin{array}{c}- \\
0.190\end{array}$ & $\begin{array}{c}0.29 \\
4\end{array}$ & 0.325 & $\begin{array}{c}0.74 \\
5\end{array}$ \\
\hline Questionable & 61 & $.149^{* * *}$ & .091 & .206 & $722.312^{* * *}$ & 0.038 & 0.000 & & & & & \\
\hline
\end{tabular}

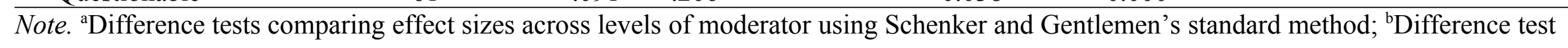

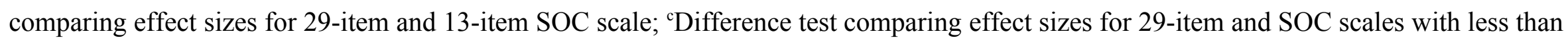

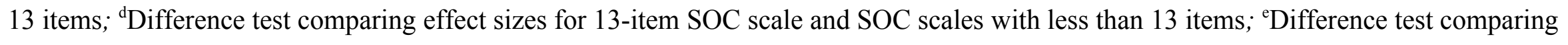


effect sizes for previously-validated physical activity scales and measures of physical activity that measured physical activity participation with bespoke questions; ${ }^{\mathrm{f}}$ Difference test comparing effect sizes for majority older and mixed age groups; ${ }^{\mathrm{g}}$ Difference test comparing effect sizes for majority older and majority younger age groups, ${ }^{\mathrm{h}}$ Difference test comparing effect sizes for mixed and majority younger age groups; ${ }^{i}$ Difference test comparing effect sizes for majority female and mixed sex groups; ${ }^{j}$ Difference test comparing effect sizes for majority female and majority male sex groups; ${ }^{k}$ Difference test comparing effect sizes for mixed and majority male sex groups; ${ }^{1}$ Difference test comparing effect sizes for measures of general physical activity and light intensity physical activity groups; ${ }^{\mathrm{m}}$ Difference test comparing effect sizes for measures of general physical activity and moderate-to-vigorous intensity physical activity groups; ${ }^{\mathrm{n}}$ Difference test comparing effect sizes for measures of general physical activity and mixed intensity physical activity groups; ${ }^{\circ}$ Difference test comparing effect sizes for measures of light intensity physical activity and moderate-to-vigorous intensity physical activity groups; ${ }^{\mathrm{p}}$ Difference test comparing effect sizes for measures of light intensity physical activity and mixed intensity physical activity groups; ${ }^{\mathrm{q}}$ Difference test comparing effect sizes for measures of moderate-to-vigorous intensity physical activity and mixed intensity physical activity groups; ${ }^{\mathrm{r}}$ Difference test comparing effect sizes for correlational study (physical activity and sense of coherence measured at same time) and experimental study (physical activity applied in intervention or measured at time 1 and sense of coherence measured at time 2 ) groups; ${ }^{\mathrm{s}}$ Difference test comparing effect sizes for measures of acceptable study quality and questionable study quality groups; $k=$ Number of studies; $r=$ Average sample-weighted correlation for the effect; $95 \% \mathrm{CI}=95 \%$ confidence intervals of the correlation; $\mathrm{LL}=$ Lower limit of the $95 \%$ confidence interval; UL $=\mathrm{Upper}$ limit of the $95 \%$ confidence interval; $Q=$ Cochrane's $Q$ statistic; $\sigma^{2}$ between = Between-study variance; $\sigma^{2}$ within $=$ Within-study variance; General $=$ General 
activity intensity (no indication of intensity reported); Light = Light level of physical activity (e.g., walking, yoga); Moderate-Vigorous = Moderate-to-vigorous physical activity intensity (e.g., aerobic, resistance training); Mixed = Included multiple intensities in a single measure.

$* p<.05 * * p<.01 * * * p<.001$ 